TITLE:

\title{
Hydrodynamics and boiling phenomena of water droplets impinging on hot solid
}

\section{$\operatorname{AUTHOR}(\mathrm{S})$ :}

Fujimoto, Hitoshi; Oku, Yosuke; Ogihara, Tomohiro; Takuda, Hirohiko

\section{CITATION:}

Fujimoto, Hitoshi ...[et al]. Hydrodynamics and boiling phenomena of water droplets impinging on hot solid. International Journal of Multiphase Flow 2010, 36(8): 620-642

\section{ISSUE DATE:}

2010-08

URL:

http://hdl.handle.net/2433/126732

\section{RIGHT:}

(C) 2010 Elsevier Ltd; この論文は出版社版でありません。引用の際には 出版社版をご確認ご利用ください。; This is not the published version. Please cite only the published version. 
Hydrodynamics and boiling phenomena of water droplets impinging on hot solid

Hitoshi Fujimoto $^{1}$, Yosuke $\mathrm{Oku}^{2}$, Tomohiro Ogihara ${ }^{2}$ and Hirohiko Takuda ${ }^{1}$

1. Graduate School of Energy Science, Kyoto University, Kyoto 606-8501, Japan

2. Graduate student at Kyoto University, Kyoto 606-8501, Japan

Corresponding Author: Associate Professor Hitoshi Fujimoto, h-fujimoto@energy.kyoto-u.ac.jp

\begin{abstract}
The collision of single water droplets with a hot Inconel 625 alloy surface was investigated by a two-directional flash photography technique using two digital still cameras and three flash units. The experiments were conducted under the following conditions: the pre-impact diameters of the droplets ranged from 0.53 to $0.60 \mathrm{~mm}$, the impact velocities ranged from $1.7 \mathrm{~m} / \mathrm{s}$ to $4.1 \mathrm{~m} / \mathrm{s}$, and the solid surface temperatures ranged from $170{ }^{\circ} \mathrm{C}$ to $500{ }^{\circ} \mathrm{C}$. When a droplet impacted onto the solid at a temperature of $170{ }^{\circ} \mathrm{C}$, weak boiling was observed at the liquid/solid interface. At temperatures of 200 or $300{ }^{\circ} \mathrm{C}$, numerous vapor bubbles were formed. Numerous secondary droplets then jetted upward from the deforming droplet due to the blowout of the vapor bubbles into the atmosphere. No secondary droplets were observed for a surface temperature of $500{ }^{\circ} \mathrm{C}$ at the low-impact Weber numbers $(\sim 30)$ associated with the impact inertia of the droplets. Experiments using 2.5-mm-diameter droplets were also conducted. The dimensionless collision behaviors of large and small droplets were compared under the same Weber number conditions. At temperatures of less than or equal to $300{ }^{\circ} \mathrm{C}$, the blowout of vapor bubbles occurred at early stages for a large droplet. At a surface temperature of $500{ }^{\circ} \mathrm{C}$, the two dimensionless deformation behaviors of the droplets were very similar to each other.
\end{abstract}

Keywords: photographic observation, droplet impact, boiling phenomena, Weber number 


\section{Introduction}

The collision of liquid droplets with solids is observed everywhere in our daily lives, and also in various industrial applications, e.g., spray cooling of hot materials (Bolle and Moureau, 1982), spray coating (Aziz and Chandra, 2000), fuel injection in combustion engines (Moita and Moreira, 2007), fire suppression using sprinkler systems (Manzello and Yang, 2002), and inkjet printing (Fukai et al., 2006). The dynamics of droplet collisions with solid substrates have fascinated numerous researchers in the area of fluid mechanics, as well as the engineers using these applications. Comprehensive reviews of related studies have been presented by Yarin (2006) and Rein $(1993,2002)$. A brief literature survey is presented in a later subsection.

When a subcooled droplet impacts onto a solid substrate heated far above the boiling temperature of the liquid, there is a direct contact between the liquid and solid. The liquid is abruptly heated above the saturation temperature at the contact point, and the temperature of the solid surface decreases sharply (Seki et al., 1978). The high rate of increase in the liquid temperature leads to rapid boiling. Since the liquid temperature is very high at the liquid/solid interface and decreases sharply away from it, boiling occurs only at or very close to the interface.

There are two types of bubble nucleation in boiling, namely heterogeneous nucleation and homogeneous nucleation (Blander and Katz, 1975; Skripov, 1974; Avedisian, 1985). In heterogeneous nucleation (Blander and Katz, 1975), vapor bubbles are generated at pre-existing nuclei such as cavities, defects, or gas pockets on the solid surface and impurities within the liquid. This boiling mechanism is dominant at temperatures lower than the limit of superheat, $T_{h n}$, at which a liquid can sustain the given pressure without undergoing a phase change.

Homogeneous nucleation occurs appreciably at temperatures higher than the limit of superheat. Nuclei are spontaneously generated in the liquid due to molecular density fluctuations and a phase change from liquid to vapor occurs abruptly (Blander and Katz, 1975). If the liquid temperature reaches the limit of superheat due to abrupt heating, both heterogeneous nucleation and homogeneous nucleation occur, resulting in the nucleation of numerous vapor bubbles (Skripov, 1974). The rapid growth and 
coalescence of the vapor bubbles leads to the formation of a thin vapor film between the liquid and the solid. The deformation mechanics of the droplet are, therefore, influenced by these boiling phenomena, which are strongly dependent on the local temperature of the solid surface.

In addition to the temperature of the solid surface, the behavior of droplets colliding with a substrate is affected by other parameters. The Weber number of the droplets, which is the ratio of the inertia force to the surface tension force, is often regarded as a key parameter (Wachters and Westerling, 1966; Bernardin et al., 1997; Yarin, 2006; Rein 1993, 2002). It can be defined by

$$
W e=\rho v^{2} d_{p} / \sigma
$$

where $\rho, v, d_{p}$, and $\sigma$ are the liquid density, impact velocity of the droplet, pre-impact diameter of the droplet, and surface tension force, respectively. If the Weber number is small, the droplet impacts onto the solid and deforms without disintegration. For large Weber numbers, splashing occurs during the collision. The droplet Reynolds number is the ratio of the inertia force to the viscous force, given by

$$
R e=\rho v d_{p} / \mu
$$

where $\mu$ is the coefficient of liquid viscosity. Further, the impact angle of droplets to the solid, the roughness of the solid surface, and the wettability between the liquid and the solid also affect the droplet collision behavior.

There have been many experimental works concerned with the collision of droplets with a hot substrate, as mentioned in a later subsection. In many of the studies, relatively large droplets with diameters larger than $1 \mathrm{~mm}$ were used, while smaller droplets are used in industrial applications. The Weber number and temperature of the solid substrate were regarded as key parameters affecting the normal collision of droplets with a smooth hot solid. If the dynamical similarity between the two droplet motions based on their Weber numbers roughly holds true, the knowledge obtained from studies on large droplets is applicable to the analysis of industrial applications. However, it is not yet clear whether the collision phenomena of relatively large droplets are really similar to those of smaller droplets. In the present study, this issue was addressed by directly comparing the deformation behaviors of large and small droplets on a hot solid 
under the same Weber number conditions. In addition, despite prior experimental studies using small droplets, the details of the deformation behavior of the droplets and the boiling phenomena remain unclear, principally because of the experimental difficulties: the deformation and boiling phenomena of droplets occur within very short spatial and temporal scales. The boiling vapor bubbles and/or disintegrated droplets formed during the impact were considerably small in size as compared to the pre-impact diameter of the droplets. Therefore, the knowledge of such motion of the small bubbles/droplets was lacking thus far and was studied in the present study through a high-resolution flash photography technique.

In the present study, the hydrodynamics and boiling phenomena of single water droplets impinging on a hot Inconel 625 alloy surface were studied experimentally. The pre-impact diameter of the droplets was approximately $0.6 \mathrm{~mm}$, and the impact velocity was in the range of $1.7 \mathrm{~m} / \mathrm{s}$ to $4.1 \mathrm{~m} / \mathrm{s}$. Droplets with diameters of approximately 2.5 $\mathrm{mm}$ were also tested to investigate the dynamical similarity of the collision behavior of droplets. For this purpose, a two-directional flash photography technique with two digital still cameras and three flash units was developed. One camera and a pair of flash units were used to obtain double-exposure backlit images of the droplets during the collisions. The other camera and a flash unit were employed for taking bird's-eye-view images of the droplets. These two types of images were obtained simultaneously so that the three-dimensional deformation behavior of the droplets could be monitored. By varying the Weber number and the temperature of the solid surface systematically, we investigated the hydrodynamics and the boiling phenomena of the droplets in detail.

\section{Literature Survey}

A literature survey of the experimental research on the collisions of droplets with solids was conducted. Wachters and Westerling (1966) investigated the impingement of subcooled water droplets with a diameter of approximately $2.0 \mathrm{~mm}$ on a polished gold surface heated to $400{ }^{\circ} \mathrm{C}$. Ueda et al. (1979) studied the impact of saturated water droplets with diameters ranging from $0.94 \mathrm{~mm}$ to $3.02 \mathrm{~mm}$ on vertically heated stainless 
steel or copper surfaces at $300{ }^{\circ} \mathrm{C}$. Akao et al. (1980) investigated the dynamics of the collisions of droplets of water, ethanol, and acetic acid, with diameters ranging from 2.1 $\mathrm{mm}$ to $2.9 \mathrm{~mm}$, with a chromium-plated solid surface at $400{ }^{\circ} \mathrm{C}$ by using high-speed photography. They reported that the disintegration characteristics of the droplets were not determined solely by their Weber numbers. Chandra and Avedisian (1991) obtained very clear bird's-eye-view images of $n$-heptane droplets impinging on a hot stainless steel surface at $24 \sim 250{ }^{\circ} \mathrm{C}$ with a Weber number of 43 by using a flash photography method, and also studied the deformation processes of $n$-heptane droplets impacting onto a hot ceramic porous surface (Chandra and C. T. Avedisian, 1992). Bernardin et al. (1997) carried out experiments investigating the impingement of water droplets on a hot aluminum surface at $100 \sim 280{ }^{\circ} \mathrm{C}$ with Weber numbers of 20, 60, and 280 and constructed regime maps showing film boiling, transition boiling, nucleate boiling, and film evaporation. Kang and Lee (2000) studied 2.3-mm-diameter water droplets impinging on a heated copper surface, using a high-speed camera to determine the effects of varying their impact angles on their deformation behavior. Inada and Yang (1993) investigated the mechanism of miniaturizing 4.0-mm-diameter water droplets impacting onto a hot platinum surface at $160 \sim 420{ }^{\circ} \mathrm{C}$. Nagai and Nishio (1996) used a flash photography method to observe the dynamic behavior of the contact between water droplets and a sapphire surface heated above the Leidenfrost temperature. Chaves et al. (1999) studied the bubble formation inside 1.8-mm-diameter ethanol droplets on a hot aluminum surface by using CCD camera photography and concluded that the growth rate of vapor bubbles is independent of the Weber number, but is dependent on the wall temperature.

The literature dealing with the collisions of small droplets with solids was also reviewed. Xiong and Yuen (1991) investigated the evaporation of droplets of water or a hydrocarbon mixture from a stainless steel surface by using a flash photography method. The initial diameters of the droplets ranged from $0.07 \mathrm{~mm}$ to $1.8 \mathrm{~mm}$, and the temperature of the solid was varied from $63{ }^{\circ} \mathrm{C}$ to $605{ }^{\circ} \mathrm{C}$. Anders et al. (1993) investigated the droplet wall interaction of ethanol droplets successively impacting onto a heated chromium-plated solid surface. The experimental conditions were as follows: 
pre-impact droplet diameters ranged from approximately $0.09 \mathrm{~mm}$ to $0.21 \mathrm{~mm}$ and surface temperatures ranged from $25^{\circ} \mathrm{C}$ to $280{ }^{\circ} \mathrm{C}$. The effects of the impact velocity on the collision dynamics were also investigated. Ko and Chung (1996) conducted experiments to investigate the break-up of small $n$-decane droplets, with diameters from approximately $0.3 \mathrm{~mm}$ to $0.5 \mathrm{~mm}$, on a hot brass surface. Karl and Frohn (2000) studied the deformation processes of small droplets of water or ethanol with diameters ranging from 0.07 to $0.26 \mathrm{~mm}$ successively impacting onto chromium-plated copper or steel surfaces heated above the Leidenfrost temperature. Chen et al. (2007) characterized the collision dynamics of diesel droplets with diameters ranging from $0.50 \mathrm{~mm}$ to $0.95 \mathrm{~mm}$ impinging on a hot inclined stainless steel surface heated to $480{ }^{\circ} \mathrm{C}$. Hatta et al. (1995) conducted experiments on the collisions between water droplets with diameters from $0.3 \mathrm{~mm}$ to $0.6 \mathrm{~mm}$ and an Inconel alloy 625 surface at $500{ }^{\circ} \mathrm{C}$, and also studied the dynamics of the collisions of water droplets with diameters of less than $1 \mathrm{~mm}$ with hot stainless-steel and silicon surfaces (Hatta et al., 1997). Mehdizadeh and Chandra (2006) used a single-shot photography method to investigate the boiling phenomena of 0.55-mm-diameter water droplets impinging on a hot stainless steel surface at high impact velocities and concluded that the temperature required for vapor bubble formation decreases with an increase in the impact velocity.

\section{Experimental Procedure}

\section{Experimental apparatus}

Figure 1 shows a schematic diagram of the experimental apparatus used to observe the impact phenomena of single water droplets on the heated surface. Distilled water at room temperature in a gas-tight tank is sent to the top of a nozzle unit equipped with a nozzle oscillator. Water flows in through the nozzle and then issues vertically downward from the flat-tipped exit. A stream of droplets with uniform diameters and uniform intervals between successive droplets can be formed below the nozzle unit by oscillating it at a certain frequency (Pedersen, 1970). The droplet diameter and spraying velocity can be adjusted by varying the water flow rate. The droplets then hit a rotating disk with 
a diameter of $200 \mathrm{~mm}$ and a small slit hole. The rotation speed of the disk was adjusted such that at most one droplet passed through the slit hole during each rotation of the disk and that the collision of a droplet with a solid substrate occurred a few times per second. An optical sensor (diode photoelectric sensor) captured the position of the slit hole in the rotating disk and provided a signal to trigger the flash photography. Because the falling water droplets were small, transparent, and relatively fast, it was difficult to directly capture them with the optical sensor.

The horizontal test piece made of Inconel alloy 625 solid (a 6-mm-thick disk with a diameter of $28 \mathrm{~mm}$ ) was firmly mounted on a copper base with an embedded cartridge electric heater. The test piece was polished with an abrasive compound before every experiment to keep the solid surface clean. The arithmetic mean surface roughness was confirmed to be within $0.3 \mu \mathrm{m}$. The surface temperature of the solid was maintained at a preset value by using K-type thermocouples with a wire having a diameter of $0.3 \mathrm{~mm}$ spot-welded on the Inconel 625 surface and a temperature controller that regulated the electric power supply to the heater. The deviation from the preset temperature during the experiments was within $\pm 10^{\circ} \mathrm{C}$.

In these experiments, the pre-impact diameter of the droplets, $d_{p}$, was varied from 0.53 to $0.60 \mathrm{~mm}$, the impact velocity, $v$, was varied from 1.7 to $4.1 \mathrm{~m} / \mathrm{s}$ (the corresponding impact Weber numbers ranged from 24 to 134), and the temperature of the solid surface, $T_{w}$, was varied from $170{ }^{\circ} \mathrm{C}$ to $500{ }^{\circ} \mathrm{C}$.

When conducting the experiments using large droplets, the rotating disk unit was removed. A very small water flow rate was supplied to the nozzle unit so that a droplet was formed at the nozzle exit, increased in size, and eventually detached due to gravity. Falling droplets with diameters of approximately $2.5 \mathrm{~mm}$ were directly captured by the optical sensor used for the strobe-light trigger signal. The impact velocity of the droplets was adjusted by varying the nozzle-to-substrate distance.

The collision behavior of the droplets will be discussed, not only in relation to the dimensional length and time, but also by using the dimensionless length and time. The dimensionless spatial scale is normalized by the pre-impact diameter of a droplet. The dimensionless time, $\tau$, normalized by the characteristic time for the impact inertia of 
droplets is given as:

$$
\tau=t_{e} /\left(d_{p} / v\right)
$$

where $t_{e}$ represents the elapsed time after the droplet touches the solid. The Weber number, as well as the Reynolds number, is evaluated, taking into account the temperature dependence of thermo-physical properties, because the liquid temperature was not maintained at a certain value. When making large droplets, the temperature of the droplets formed at the nozzle tip became higher than the liquid in the water tank because of radiation heat transfer from the hot test piece to the nozzle tip.

\section{Photography and measurement procedure}

The collisions between the droplets and the solid were three-dimensional, so a two-directional observation technique was developed that used two digital still cameras (Canon EOS Kiss Digital X2) with an effective spatial resolution of $3888 \times 2592$ pixels and three microflash units (Sugawara MS-230A). Figure 2 shows a schematic diagram of the photography setup. One camera, the test piece, and a pair of flash units were aligned horizontally to obtain side-view, double-exposed, and backlit images of the droplets. Another camera and flash unit were arranged to provide bird's-eye-view images of the droplets. For convenience, these camera arrangements are denoted Camera A and Camera B, respectively. The exposure time for both cameras was set at $1 / 2$ or $1 \mathrm{~s}$, which was sufficiently longer than the duration of the flash $(\sim 2 \mu \mathrm{s})$. When trigger signals appeared, a flash controller (Sugawara RE307-U2) activated the three flash units independently at different preset delay times. The timing of each flash activation could be controlled with a resolution of $1 \mu \mathrm{s}$. The droplet images were exposed only when the flash units were triggered.

For Camera A, the two flashes (light A and light B) were operated consecutively at a preset time interval such that backlit double-exposed photographs of the droplets could be obtained. Figure 3 shows examples of the double-exposed images of the droplets. The time intervals between the two flashes were (a) $0.50 \mathrm{~ms}$ and (b) $0.70 \mathrm{~ms}$. Note that one flash bulb was colored red so that the images of the droplets exposed at the first and second flashes could be easily distinguished. In (a), the time interval between the two 
flashes is small. Neither droplet has reached the solid surface even after the second flash. The pre-impact diameter of each droplet, $d_{p}$, was determined directly from the images of the droplet by using the image analyzing software Adobe Photoshop CS3 Extended. The impact velocity of the droplet, $v$, was also determined from the time interval, $\Delta t$, between the two flashes and the distance, $\Delta L$, moved by the droplet:

$$
v=\Delta L / \Delta t
$$

In addition, the uncertainty in the measurement of the spatial length, which depends on the magnification of the lens system (Canon MP-E $65 \mathrm{~mm}$ ), was at worst within $\pm 3 \mu \mathrm{m}$ for the cases of small droplets.

In (b), the first flash was triggered before the impact of the droplet, and the second flash was activated after the impact. The elapsed time can be determined from the spacing, $\Delta L_{w}$, between the bottom of the droplet at the first flash and the solid, the impact velocity, and the time interval as follows:

$$
t_{e}=\Delta t-\Delta L_{w} / v
$$

The time evolution of the droplet shape was followed by taking instantaneous images with various time intervals between the two flashes $(0.3-5.0 \mathrm{~ms}$ for small droplets and 3-30 ms for large droplets). It should be noted that there was a slight scatter in the pre-impact diameter, as well as in the impact velocity, in these experiments. Thus, the droplet diameter and spacing were measured for every image and irregular data were removed to minimize the experimental uncertainties. The allowable deviation of the pre-impact diameter and the impact velocity were set within $\pm 10 \mu \mathrm{m}$ and $0.05 \mathrm{~m} / \mathrm{s}$ for small droplets, respectively. For example, if the diameter was $d_{p}=0.60 \mathrm{~mm}$, its scatter range would be between $0.59 \mathrm{~mm}$ and $0.61 \mathrm{~mm}$. The scatter range of the pre-impact diameter and the impact velocity were within $\pm 60 \mu \mathrm{m}$ and $0.02 \mathrm{~m} / \mathrm{s}$ for large droplets, respectively.

Camera A was suitable for accurate measurements of the impact conditions (the pre-impact diameter of the droplet, the impact velocity of the droplet, and the time after the impact of the droplet) and for following the time evolution of the shape of the droplet. However, the three-dimensional shape of the droplet could not be determined from its images, nor could the boiling phenomena occurring inside the droplet be 
observed. To eliminate these disadvantages, Camera B was added, as shown in Figure 2. Camera B was tilted obliquely downward to provide bird's-eye-view images of the droplet. The angle of tilt, $\alpha$, of the camera and the position of light $\mathrm{C}$ were carefully adjusted in each experiment, because the quality of the droplet images obtained with Camera B was very sensitive to these factors, and the optimal angle was dependent on the impact conditions. The flash unit for Camera B was operated only once, when the second flash for Camera A was activated. Thus, two types of images for the droplets were obtained simultaneously with Cameras A and B.

\section{Estimation of the interfacial temperature and the limit of superheat}

The temperature at the droplet/solid interface is a key factor in investigating the boiling phenomena. According to some recent works, the local temperature distribution on a small area can be measured with a high resolution by using a diode temperature sensor array (Han and Kim, 2008) and micro-thermocouple arrays (Auracher and Marquardt, 2004). Tartarini et al. (2009) used infrared-transparent $\mathrm{BaF}_{2}$ crystals to non-intrusively measure the interface temperature with an infrared camera. However, it would be difficult to correctly measure the local temperature experimentally without using such measurement devices. Instead, the temperature at the liquid/solid interface at the moment of impact can be estimated with a simple one-dimensional theory (Seki et al., 1978; Aziz and Chandra, 2000; Bernardin and Mudawar, 1999, 2002, 2004; Cossali et al., 2008; Furuya and Arai, 2008). According to the one-dimensional transient heat conduction theory for interfacial contact between two semi-infinite solids with different temperatures (Carslaw and Jaeger, 1959; Eckert and Drake, 1972), the interfacial temperature, $T_{i}$, is given by

$$
T_{i}=\frac{T_{H} \sqrt{\rho_{H} C_{P H} \lambda_{H}}+T_{C} \sqrt{\rho_{C} C_{P C} \lambda_{C}}}{\sqrt{\rho_{H} C_{P H} \lambda_{H}}+\sqrt{\rho_{C} C_{P C} \lambda_{C}}},
$$

where $\left(T_{C}, T_{H}\right),\left(\rho_{C}, \rho_{H}\right),\left(C_{P C}, C_{P H}\right)$, and $\left(\lambda_{C}, \lambda_{H}\right)$ are the temperatures, densities, specific heats, and thermal conductivities of the two materials $(C$ and $H)$, respectively. According to Eq. (6), this theory indicates that the interfacial temperature is independent of the time elapsed after the contact of the two materials. In reality, however, the 
interfacial temperature decreases with time because of convection, phase changes, and axisymmetric/three-dimensional heat transfer (Aziz and Chandra, 2000). In addition, a temperature jump could be present at the interface. Therefore, Eq. (6) can be used for rough evaluations of the interfacial temperature at the moment of droplet impact.

According to the literature (Skripov, 1974; Lienhard, 1976; Avedisian, 1985; Derewnicki, 1985; Iida etal., 1994; Avedisian et al., 1999; Glod et al., 2002; Thomas et al., 2003; Hong et al., 2004), the limit of superheat of water at atmospheric pressure lies in the range $T_{h n}=283-313{ }^{\circ} \mathrm{C}$. The critical temperature of water is $374{ }^{\circ} \mathrm{C}$. If the calculated interfacial temperature becomes higher than the limit of superheat, the temperature calculated by Eq. (6) has no physical meaning. In such a case, a vapor film is formed between the liquid and solid immediately after the droplet impact. Although the time required for forming vapor layers cannot be measured correctly, it must be very short compared to the characteristic time scales $\left(d_{p} / v\right)$ in the present experiments (Glod et al., 2002).

\section{Observations of impact phenomena of single droplets for small low Weber numbers}

The collisions of single water droplets with a hot solid were investigated with the observation techniques described above. The experiments were conducted for small Weber numbers (We $\sim 30$ ). Figure 4 depicts the deformation behavior of a water droplet impacting horizontally on the Inconel 625 alloy surface at $170{ }^{\circ} \mathrm{C}$ for $d_{p}=0.60 \mathrm{~mm}$ and $v=2.1 \mathrm{~m} / \mathrm{s}(\mathrm{We}=36)$. Figure $4(\mathrm{a})$ and $4(\mathrm{~b})$ show side-view images of the droplet obtained by the double-exposure method using Camera A and the bird's-eye-view images taken using Camera B, respectively. The elapsed times, $t_{e}$, after the impact of the droplet on the surface are given in the images. The dimensionless elapsed times, $\tau$, normalized by $\left(d_{p} / v\right)$ are also shown. A circular thin liquid jet is formed around the bottom of the droplet and spreads radially (see Figure 4(a)). The thickness of the droplet at the center decreases monotonically ( $t_{e}=0.04-0.47 \mathrm{~ms}$ ). The droplet deforms into a thin circular disk. In Figure 4(b), a single bubble indicated by an arrow is formed at the impact point $\left(t_{e}=0.04 \mathrm{~ms}\right)$, which is caused by the entrapment of air at the impact 
point (Chandra and Avedisian, 1991; Pasandideh-Fard et al., 1996; Mehdi-Nejad et al., 2003; Fujimoto et al., 2000, 2004; Thoroddsen et al., 2003, 2005). At $t_{e}=0.10 \mathrm{~ms}$ and $0.19 \mathrm{~ms}$, additional bubbles are seen around this single bubble. Thereafter, isolated bubbles are observed in the rim of the liquid film caused by boiling or the deposition of dissolved air in the liquid. After the liquid film spreads to its maximal extension $\left(t_{e} \sim\right.$ $0.59 \mathrm{~ms}$ ), the constriction of the liquid film commences. It is seen from (a) that the contact diameter of a droplet decreases with time, while the height increases slightly. The liquid deforms into a convex lens shape at $t_{e}=1.37 \mathrm{~ms}$.

Figure 5 depicts a sequence of images showing the collision dynamics of a water droplet impinging on a surface heated to $T_{w}=200{ }^{\circ} \mathrm{C}$. The pre-impact diameter of the droplet was $d_{p}=0.56 \mathrm{~mm}$ and the impact velocity was $v=1.8 \mathrm{~m} / \mathrm{s}$. The corresponding Weber number is 26 . At $t_{e}=0.07 \mathrm{~ms}$ in (b), a bubble indicated by an arrow is seen at the impact point. Boiling vapor bubbles are generated at the liquid/solid interface at $t_{e}=0.12$ and $0.17 \mathrm{~ms}$. At $t_{e}=0.26$ and $0.39 \mathrm{~ms}$ in (a), small droplets can be seen above the body of the liquid. For convenience, these small droplets are called "secondary droplets." The formation of secondary droplets can be explained by the following mechanism: after the droplet impacts on the solid, boiling occurs at the liquid/solid interface. The boiling vapor bubbles grow larger at the liquid/solid interface and can become detached from the solid. At the same time, the droplet deforms into a thin circular disk. As a consequence, the upper sides of the vapor bubbles reach the free liquid surface (the liquid/atmospheric air interface) and then blow out to the atmosphere, accompanied by many secondary droplets flying upward. The free surface in the center part of the liquid is smooth at $t_{e}=0.26 \mathrm{~ms}$ in Figure. 5(b), while the other part is lumpy, so the secondary droplets are mainly jetted from the thin circular film part. After $t_{e}=0.53 \mathrm{~ms}$, secondary droplets are jetted from all areas of the liquid. Larger secondary droplets appear at later times $\left(t_{e}=0.53-1.17 \mathrm{~ms}\right)$, as shown in Figure 5(a), and are probably due to the bursting of larger vapor bubbles at the free surface. At $t_{e}=$ $1.17 \mathrm{~ms}$, the free surface of the liquid is entirely distorted. At $t_{e}=2.93 \mathrm{~ms}$, most of the liquid is separated from the solid surface, but some liquid is still in direct contact with the solid surface. 
Figure 6 shows the deformation behavior of a water droplet on the hot surface at $T_{w}$ $=200{ }^{\circ} \mathrm{C}$ for $d_{p}=0.57 \mathrm{~mm}$ and $v=1.7 \mathrm{~m} / \mathrm{s}(\mathrm{We}=24)$. These droplet images were obtained using a different magnification for the lens system and a different angle of tilt for light $\mathrm{C}$ in order to investigate the boiling phenomena during the initial stages of the collision. At $t_{e}=0.03 \mathrm{~ms}$ and $0.07 \mathrm{~ms}$, some bubbles appear inside the liquid. The number of bubbles in the central part of the droplet apparently increases at $t_{e}=0.11$ ms. In the circular thin film region, bubbles are seen in the form of a ring, as indicated by an arrow. Thereafter, the bubbles increase in size due to heat transfer from the solid and/or the coalescence of adjacent bubbles. At $t_{e}=0.19 \mathrm{~ms}$, the blowout of vapor bubbles occurs in the circular periphery, as indicated by an arrow. The droplet is filled with numerous vapor bubbles on a very short time scale.

Figure 7 depicts the deformation behavior of a water droplet on the solid surface at $T_{w}=300{ }^{\circ} \mathrm{C}$ for $d_{p}=0.58 \mathrm{~mm}$ and $v=2.1 \mathrm{~m} / \mathrm{s}(\mathrm{We}=34)$. At $t_{e}=0.12 \mathrm{~ms}$ in $(\mathrm{b})$, small bubbles are present inside the droplet. The generation of secondary droplets is seen at $t_{e}=0.27 \mathrm{~ms}$, as shown in (a). The apparent liquid/solid contact area decreases with time $\left(t_{e}=0.27-0.67 \mathrm{~ms}\right)$, suggesting that direct liquid/solid contact is dramatically reduced by the presence of the vapor bubbles or a thin vapor film at the liquid/solid interface. At $t_{e}=0.45 \mathrm{~ms}$ and $0.58 \mathrm{~ms}$ in (b), the droplet is significantly distorted. Thereafter, the distorted liquid moves radially inward. Eventually, most of the liquid becomes separated from the solid surface $\left(t_{e}=1.30 \mathrm{~ms}\right)$.

The interfacial temperatures calculated by Eq. (6) for our system are $T_{i}=141{ }^{\circ} \mathrm{C}$ for $T_{w}=170{ }^{\circ} \mathrm{C}, T_{i}=167{ }^{\circ} \mathrm{C}$ for $T_{w}=200{ }^{\circ} \mathrm{C}$, and $T_{i}=251^{\circ} \mathrm{C}$ for $T_{w}=300{ }^{\circ} \mathrm{C}$. The vapor bubbles in Figures 4 to 7 are thus caused by heterogeneous nucleation. The number of vapor bubbles at $T_{w}=170{ }^{\circ} \mathrm{C}$ is appreciably fewer than the case of $200{ }^{\circ} \mathrm{C}$, although the temperature difference is only $30^{\circ} \mathrm{C}$. Wang and Cheng (2009) reported that the heat flux from the solid to the liquid dramatically increases when the value of $T_{i}$ is more than $140^{\circ} \mathrm{C}$, where the vapor nuclei become very active. Taking into account the fact that the actual interfacial temperature decreases with time, the present data are consistent with the results of Wang and Cheng (2009).

It should be noted that the formation of a vapor film is possible not only in the 
temperature range of homogeneous nucleation, but also at lower temperatures. The time required for the formation of a vapor film is much shorter in the homogeneous nucleation regime than at lower temperatures, because the number of nucleation points and the growth rate of each bubble are very large. For the case of $T_{w}=300{ }^{\circ} \mathrm{C}$, the calculated interfacial temperature is less than the limit of superheat. Nevertheless, the growth and coalescence of vapor bubbles due to heterogeneous nucleation prevent direct liquid/solid contact and a vapor layer is probably formed at later times.

Figure 8 shows the deformation behavior of a water droplet on the solid surface at $400{ }^{\circ} \mathrm{C}$ for $d_{p}=0.57 \mathrm{~mm}$ and $v=1.9 \mathrm{~m} / \mathrm{s}(\mathrm{We}=28)$. The droplet impacts, spreads radially over the solid, and deforms into a thin circular disk $\left(t_{e}=0.09-0.30 \mathrm{~ms}\right)$. Unlike the cases discussed above, the shape of the droplet remains almost axisymmetric. After the droplet reaches its maximal extension, it constricts due to surface tension (Hatta et al., 1997). At $t_{e}=0.42 \mathrm{~ms}$, some secondary droplets are jetted upward from the thin liquid. At $t_{e}=0.55 \mathrm{~ms}$ in (b), a dry area appears in the central part formed by the blowout of bubbles. As the droplet constricts, its diameter decreases and its height increases. At $t_{e}=1.42 \mathrm{~ms}$, the droplet separates from the surface and its shape looks like a bowling pin, in which small vapor bubbles are observed.

For the case of $T_{w}=400{ }^{\circ} \mathrm{C}$, the interfacial temperature was calculated to be $T_{i}=$ $338{ }^{\circ} \mathrm{C}$, which is a little higher than the temperature required for homogeneous nucleation. At $t_{e}=0.09 \mathrm{~ms}$ in Figure 8(b), the liquid/solid interface looks hazy, so a vapor layer probably exists there. The interfacial temperature soon decreases below the limit of superheat due to convection and rewetting (liquid/solid contact) occurs locally. As a consequence, vapor bubbles are formed at the cavities on the solid surface in the rewetting areas. This results in the formation of secondary droplets that are jetted upward from the center of the thin circular liquid at later times.

Figure 9 depicts the deformation behavior of a water droplet on the hot surface at $T_{w}$ $=500{ }^{\circ} \mathrm{C}$ for $d_{p}=0.58 \mathrm{~mm}$ and $v=2.0 \mathrm{~m} / \mathrm{s}(\mathrm{We}=33)$. The estimated interfacial temperature is $T_{i}=426{ }^{\circ} \mathrm{C}$, which is higher than the critical temperature of water $\left(374{ }^{\circ} \mathrm{C}\right)$. The droplet impacts on the solid surface, and then spreads radially. The liquid film reaches its maximum extension $\left(t_{e} \sim 0.32 \mathrm{~ms}\right.$ ), and then constricts. The liquid is 
elongated upward in the shape of a bowling pin and rebounds off the heated surface. The flying droplet then splits into two parts $\left(t_{e}=1.58 \mathrm{~ms}\right)$. Although bubbles are present in the droplet, no secondary droplets are produced in the entire deformation process, unlike the cases in which the surface has a lower temperature. In addition, the number of vapor bubbles in the flying droplet as indicated by arrows is smaller than in the case for which the surface temperature is $400{ }^{\circ} \mathrm{C}$ (see the image at $t_{e}=1.42 \mathrm{~ms}$ in Figure $8(b)$ ) because of less direct liquid/solid contact. It should be noted that a similar droplet deformation behavior was observed for $T_{w}=450{ }^{\circ} \mathrm{C}$. Thus, the critical temperature at which the formation of secondary droplets occurs for $\mathrm{We} \sim 30$ is between $T_{w}=400{ }^{\circ} \mathrm{C}$ and $450{ }^{\circ} \mathrm{C}$.

\section{Collision phenomena of droplets with a highly heated substrate at high Weber numbers}

The deformation behaviors of droplets striking a solid heated to $400{ }^{\circ} \mathrm{C}$ and $500{ }^{\circ} \mathrm{C}$ at larger Weber numbers were investigated. Figure 10 shows the collision of a water droplet with the solid surface at $T_{w}=400{ }^{\circ} \mathrm{C}$ for $d_{p}=0.54 \mathrm{~mm}$ and $v=3.0 \mathrm{~m} / \mathrm{s}$ $(\mathrm{We}=65)$. The droplet spreads further and the liquid thickness is less than the case of Figure 8 . The periphery of the circular thin jet becomes wavy earlier and subsequently the fingering of the free liquid surface in the periphery can be clearly seen in (b). At $t_{e}$ $=0.27 \mathrm{~ms}$ and $0.35 \mathrm{~ms}$ in (a), numerous secondary droplets are observed above the upper surface of the thin liquid. At $t_{e}=0.35 \mathrm{~ms}$, the liquid film is broken locally and some dry areas are formed as indicated by arrows. The dry areas then increase in size and number $\left(t_{e}=0.35-0.45 \mathrm{~ms}\right)$. At $t_{e}=0.54 \mathrm{~ms}$, the droplet is split into many small droplets that are much larger than the secondary droplets jetted upward. All of the disintegrated parts levitate from the surface and fly radially outward.

Figure 11 shows the results for $T_{w}=500{ }^{\circ} \mathrm{C}, d_{p}=0.53 \mathrm{~mm}$, and $v=3.2 \mathrm{~m} / \mathrm{s}(\mathrm{We}$ =76). The deformation behavior of the droplet in (b) is similar to that of the collision shown in Figure 10 up to $t_{e} \sim 0.5 \mathrm{~ms}$, but a fewer secondary droplets are ejected. At $t_{e}$ $=0.54 \mathrm{~ms}$, the droplet has partially disintegrated. Although the Weber number for Figure 11 is larger than that for Figure 10, most of the droplet does not break. The 
droplet fragments then move radially inward $\left(t_{e}=0.61,0.75 \mathrm{~ms}\right)$ and coalesce again.

Figure 12 shows the deformation behavior of a water droplet on the solid surface at $500{ }^{\circ} \mathrm{C}$ for $d_{p}=0.57 \mathrm{~mm}$ and $v=4.1 \mathrm{~m} / \mathrm{s}(\mathrm{We}=134)$. The edge of the radially spreading jet consists of a ring of small droplets at $t_{e}=0.08 \mathrm{~ms}$, as shown in (b). Some of these small droplets break away from the main body of the liquid at $t_{e}=0.26 \mathrm{~ms}$ and fly radially outward. Such disintegration phenomena occur due to the large inertia of spreading liquid. At $t_{e}=0.39-0.50 \mathrm{~ms}$ in (b), dry areas appear in the thin film part. Also, in (a), small secondary droplets are observed above the upper surface of the liquid film. The liquid thickness is thinner for a larger impact inertia (Weber number) and the vapor bubbles are present in the liquid even for $T_{w}=500{ }^{\circ} \mathrm{C}$, as shown in Figure 9(b). The small droplets must be formed due to the blowout of the vapor bubbles and/or a vapor layer with a locally large thickness. Eventually the liquid film disintegrates into numerous particles and separates from the surface.

\section{Discussion}

The Weber number has been regarded as a key parameter for the collision of droplets with a hot solid (Wachters and Westerling, 1966; Bernardin et al., 1997; Yarin, 2006; Rein 1993, 2002). For example, the critical boundary, at which the disintegration of droplet occurs, has been discussed in relation to the Weber number (Wachters and Westerling, 1966; Hatta etal., 1995). In addition, it has been proposed that the maximum spreading diameter of droplets could be predicted as a function of the Weber number (Ueda et al., 1979; Akao et al., 1980; Chandra and Avedisian, 1991; Hatta etal., 1997; Karl and Frohn, 2000). Such predictions are in moderate agreement with experiments. In a strict sense, droplet collision phenomena cannot be correlated by the Weber number alone, because of the presence of other parameters affecting the motion of droplets. This section discusses additional experiments that were conducted using droplets with diameters of approximately $2.5 \mathrm{~mm}$ and the results are compared to the experimental data for the droplets with diameters of approximately $0.6 \mathrm{~mm}$ under a fixed Weber number and a fixed temperature for the solid. The conditions are investigated for which the dynamical similarity roughly holds true based on the Weber number. 
Figure 13 depicts the time evolution of the shape of the droplets for $T_{w}=170{ }^{\circ} \mathrm{C}$, $d_{p}=2.51 \mathrm{~mm}$, and $v=1.00 \mathrm{~m} / \mathrm{s}(\mathrm{We}=34)$. The droplet impacts, spreads, and deforms into a circular disk. Overall, the deformation behavior of the droplet looks similar to that in Figure 4 at early dimensionless times $(\tau=0 \sim 1.66)$. Many vapor bubbles are seen at the liquid/solid interface at $\tau=2.08$. The number of vapor bubbles is appreciably larger than the case of Figure 4. This can be explained as follows: Bubble nucleation is dependent on the temperature of the solid, the surface profile of the solid substrate, and the combination of liquid and solid materials. Moreover, the gas (air) dissolved in the liquid affects the boiling phenomena (Cui et al., 2001). Although the temperatures of the solid surfaces during the collisions could have been slightly different in the two experiments due to the bulk motion of liquid, the other parameters were the same. Thus, the number of vapor bubbles per unit area must be comparable. The dimensional liquid/solid contact area is larger for a larger droplet, resulting in the formation of more bubbles.

There have been several theoretical models for predicting the growth process for a single vapor bubble in a uniformly superheated liquid (Lee and Merte, 1996), although the theories are not directly applicable to the present cases. As is obvious, the spatial and temporal scales of the growing vapor bubbles given by the theories are independent of the pre-impact diameter of the droplet and the characteristic time, $d_{p} / v$. It follows that the liquid motion caused by the boiling phenomena has no similarity based on these characteristic scales. In Figure 13, the free liquid surface becomes very lumpy due to the blowout of vapor bubbles at a later time. In contrast, the blowout of bubbles is rare in Figure 4 and the free liquid surface is very smooth. The dimensional time scale is too small for the bubbles to increase in size.

Figure 14 shows the results for $T_{w}=200{ }^{\circ} \mathrm{C}, d_{p}=2.50 \mathrm{~mm}$, and $v=0.87 \mathrm{~m} / \mathrm{s}$ $(\mathrm{We}=26$ ). The blowout of vapor bubbles takes place in the peripheral thin film part immediately after the collision $(\tau=0.29$ and 0.39$)$, causing numerous secondary droplets to fly outward ( $\tau=0.56$ and 0.80$)$. The blowout of vapor bubbles occurs in the entire process. In contrast, in the case of Figure 5, the formation of the secondary droplet and the break in the peripheral liquid film are seen at later times. The number of 
disintegrated droplets associated with the bubble nucleation is small because the time available for the bubbles to grow is short and the dimensional liquid/solid contact area is small.

Figure 15 shows the results for $T_{w}=300{ }^{\circ} \mathrm{C}, d_{p}=2.50 \mathrm{~mm}$ and $v=1.01 \mathrm{~m} / \mathrm{s}$ $(\mathrm{We}=34)$. The blow out of vapor bubbles occurs at earlier dimensionless times in the spreading process compared to the case of Figure 7. Several dry areas are seen in the thin liquid film at $\tau=2.09$, and subsequently the liquid is split into small droplets. Many disintegrated droplets fly radially outward, unlike the case of Figure 7. It was concluded that the collision phenomena of large and small droplets do not show dynamical similarity in the heterogeneous boiling regime, where the estimated interfacial temperatures are less than the limit of superheat, because boiling vapor bubbles play an important role in the fragmentation of droplets.

Figure 16 represents the results for $T_{w}=400{ }^{\circ} \mathrm{C}, d_{p}=2.42 \mathrm{~mm}$ and $v=0.90 \mathrm{~m} / \mathrm{s}$ $(\mathrm{We}=26)$. The time evolution of the droplet shape shows a trend that is very similar to the case of Figure 8. At $\tau=0.34$, the liquid/solid interface looks hazy, probably due to the presence of a vapor film. The liquid/solid direct contact is prevented until rewetting occurs. As a consequence, the droplet shape in the spreading process shows a trend that is very similar to that of Figure 8. Thereafter, the deformation behaviors of small and large droplets remain similar. The secondary droplets are jetted and a dry area appears at the impact point at $\tau=1.86$. Eventually, the droplet rebounds off the solid at $\tau=4.63$. The number of bubbles contained in the rebounding droplet is apparently large compared to Figure 8 because of a larger liquid/solid direct contact area in the rewetting time stage.

Figure 17 shows the results for $T_{w}=500{ }^{\circ} \mathrm{C}, d_{p}=2.50 \mathrm{~mm}$, and $v=1.00 \mathrm{~m} / \mathrm{s}$ $(\mathrm{We}=33)$. The droplet impacts, spreads, reaches a maximum extension, recoils, and rebounds off. As a whole, the collision behavior of the droplets is similar to the case of Figure 9, although the detailed shapes of the droplets are slightly different. At the temperatures of $T_{w}=400{ }^{\circ} \mathrm{C}$ and $500{ }^{\circ} \mathrm{C}$, the formation of isolated vapor bubbles during the collision is far less than the cases with lower temperatures. The effect of isolated bubbles on the collision behavior is thus small. 
In the cases of $T_{w}=170{ }^{\circ} \mathrm{C}$ and $T_{w}=500{ }^{\circ} \mathrm{C}$, the droplets maintain an almost axisymmetric shape in all of the time stages. A quantitative comparison of the results for small droplets and large droplets was conducted by measuring the time evolution of the droplet diameter. Figure 18 represents the time evolutions of the dimensionless diameters, $d / d_{p}$, of droplets on the solid for (a) $T_{w}=170{ }^{\circ} \mathrm{C}$ and (b) $500{ }^{\circ} \mathrm{C}$. The definition of the diameter, $d$, of a droplet is given in Figure 18(c). The Weber numbers are similar for all of the results, but the Reynolds numbers for larger droplets are approximately two times larger than those for small droplets. In (a), the droplet diameters increase with time, reach a maximum extension, and then decrease. An appreciable difference between the two results is seen. At $T_{w}=170{ }^{\circ} \mathrm{C}$, the bubble nucleation is weak and the liquid is in direct contact with the solid substrate. Since the wall friction and internal viscous shear stress reduce the momentum of the radially spreading liquid, the dimensionless diameter of the droplets is smaller for a smaller Reynolds number.

In (b), the two droplet diameter time histories are similar to each other, although a larger droplet rebounds off at an earlier dimensionless time. Since the liquid is almost isolated from the solid surface through a vapor layer, the effect of the Reynolds number, as well as the isolated vapor bubbles, is very small. As a consequence, the dynamical similarity of the two liquid motions roughly holds true by using the Weber number alone. In addition, the maximum spreading diameters of the droplets in (b) are small compared to the cases of $T_{w}=170{ }^{\circ} \mathrm{C}$. This is because the wettability between the liquid and the substrate is better (associated with a smaller contact angle) for a lower temperature.

Incidentally, there are some experimental difficulties in forming large droplets by the simple drip method. The large droplets detach from the nozzle in the shape of teardrops and then fall vertically downward with oscillation. In a strict sense, the large droplets are not spherical in shape at the moment of impact because the nozzle-to-substrate distance $(\sim 50 \mathrm{~mm})$ is not large enough to damp the oscillation due to viscosity. In contrast, the small droplets are spherical. These facts might cause some difference between the two deformation behaviors of droplets. 
The deformation behaviors of droplets at higher Weber numbers are now investigated. Figure 19 shows the results for $T_{w}=400{ }^{\circ} \mathrm{C}, d_{p}=2.47 \mathrm{~mm}$, and $v=1.40 \mathrm{~m} / \mathrm{s}(\mathrm{We}$ $=65$ ). Figure 20 shows the results for $T_{w}=500{ }^{\circ} \mathrm{C}, d_{p}=2.59 \mathrm{~mm}$, and $v=1.48$ $\mathrm{m} / \mathrm{s}(\mathrm{We}=76)$. As can be seen in the results shown in Figures 10 and 19 and Figures 11 and 20, the collision behaviors of large and small droplets look very similar to each other.

One important issue for the use of Eq. (6) is that the interfacial temperature is a function of both the liquid and the solid thermal properties. It follows that the boiling phenomena, as well as the collision behavior of droplets, are dependent on the type of solid materials, even at a fixed surface temperature for the solid. To obtain a different interfacial temperature, 3- $\mu \mathrm{m}$ diameter diamond particles, which have a much larger thermal conductivity than Inconel alloy, were sprayed on the test piece to temporally form a thin layer of diamond particles on the surface. An additional experiment was then conducted with this ad hoc test piece. Figure 21 represents the results for $d_{p}=$ $2.57 \mathrm{~mm}$ and $v=1.06 \mathrm{~m} / \mathrm{s}(\mathrm{We}=39)$. The surface temperature of $T_{w}=170{ }^{\circ} \mathrm{C}$ is the same as the case of Figure 13, but the interfacial temperature is higher. It is obvious that more bubbles are formed than seen in Figure 13. The boiling phenomena are dependent on the type of solid material. Equation (6) is thus more appropriate than the surface temperature for characterizing the hydrodynamics and boiling phenomena of droplets. In addition, the deformation behaviors of large droplets on the two types of substrates become similar at later times because the heat capacity of the thin diamond layer is very small and the interfacial temperatures in the two cases become comparable.

\section{Conclusions}

In the present study, the collision of single water droplets with a hot Inconel alloy 625 surface was investigated experimentally by means of a two-directional flash photography technique. This observation technique was found to be sufficiently powerful for our investigation of three-dimensional droplet motion and boiling phenomena. 
The boiling phenomena can be roughly explained in terms of the interfacial temperature given by Eq. (6) and the limit of superheat. It was found that Eq. (6) is more appropriate than the surface temperature for characterizing the hydrodynamics and boiling phenomena of droplets.

In the heterogeneous boiling regime, where the interfacial temperature is less than the limit of superheat, vapor bubbles are formed at the liquid/solid interface. The blowout of vapor bubbles into the atmosphere gives rise to secondary droplets. At interfacial temperatures higher than the limit of superheat, a vapor film is formed immediately after the collision. However, isolated vapor bubbles are present inside the droplets even at $T_{w}=500{ }^{\circ} \mathrm{C}$.

The deformation behaviors of small and large droplets were compared under the same Weber number conditions. The dynamical similarity of the liquid motion is roughly obtained by the Weber number alone in the homogenous boiling regime. At lower temperatures, the deformation behaviors of droplets are affected by the Reynolds number, the contact angle, and the motion of boiling vapor bubbles whose spatial and temporal scales are independent of the pre-impact diameter of the droplets and $d_{p} / v$. The dimensionless times at which the secondary droplets are formed differ according to the droplet size.

\section{Acknowledgement}

The present study was supported by a Grant-in-Aid for Scientific Research (\#21560212) from the JSPS.

\section{References}

Akao, F., Araki, K., Mori, S. and Moriyama, A., 1980. Deformation Behaviors of a Liquid Droplet Impinging onto Hot Metal Surface, Trans. Iron Steel Inst. Japan 20, 737-743.

Anders, K., Roth, N. and Frohn, A., 1993. "The velocity change of ethanol droplets during collision with a wall analysed by image processing”, Exp. Fluids 15, 380-387.

Auracher, H. and Marquardt, W., 2004. Heat transfer characteristics and 
mechanisms along entire boiling curves under steady-state and transient conditions, Int. J. Heat and Fluid Flow, 25, 223-242.

Avedisian, C. T., 1985. The homogenous nucleation limits of liquids, J. Phys. Chem. Data 14, 695-729.

Avedisian, C. T., Osborne, W. S., Mcleod, F. D. and Curley, C. M., 1999. Measuring bubble nucleation temperature on the surface of a rapidly heated thermal ink-jet heater immersed in a pool of water, Proc. R. Soc. A 455, 3875-3899.

Aziz, S. D. and Chandra, S. , 2000. Impact, recoil and splashing of molten metal droplets, Int. J. Heat Mass Transfer 43, 2841-2857.

Blander, M. and Katz, J. L., 1975. Bubble nucleation in liquids, AIChE J. 21, 833-848.

Bernardin, J. D., Stebbins, C. J. and Mudawar, I., 1997. Mapping of impact and heat transfer regimes of water drops impinging on polished surface, Int. J. Heat Mass Transfer 40, 247-267.

Bernardin, J. D. and Mudawar, I., 1999. The Leidenfrost Point: Experimental Study and Assessment of existing Models, ASME J. Heat Transfer 121, 894-903.

Bernardin, J. D. and Mudawar, I., 2002. A Cavity Activation and Bubble Growth Model of the Leidenfrost Point, ASME J. Heat Transfer 124, 864-874.

Bernardin, J. D. and Mudawar, I., 2004. A Leidenfrost Point Model for Impinging Droplets and Sprays, ASME J. Heat Transfer 126, 272-278.

Bolle, L. and Moureau, J. C., 1982. Spray Cooling of Hot Surfaces, Multiphase Science and Technology 1, Hemisphere Pub. Corp., 1-97.

Carslaw, H.S. and Jaeger,J.C., 1959. Conduction of Heat in Solids $2^{\text {nd }}$ Edition, Oxford University Press, Oxford, 88.

Chandra, S. and Avedisian, C. T., 1991. On the collision of a droplet with a solid surface, Proc. R. Soc. Lond. A 432, 13-41.

Chandra, S. and Avedisian, C. T., 1992. Observations of droplet impinging on a ceramic porous surface, Int. J. Heat Mass Transfer 35, 2377-2388.

Chaves, H., Kubitzek, A. M. and Obermeier, F., 1999. Dynamic processes occurring during the spreading of thin liquid films produced by drop impact on hot walls, Int. J. Heat Fluid Flow 20, 470-476.

Chen, R. - H. , Chiu, S. - L. and Lin, T. - H., 2007. On the collision behaviors of a diesel drop impinging on a hot surface, Exp. Therm. Fluid Sci. 32, 587-595.

Cossali, G. E., Marengo, M. and Santini, M., 2008. Thermally induced secondary drop atomisation by single drop impact onto heated surfaces, Int. J. Heat Fluid Flow 29, 167-177.

Cui, Q., Chandra, S., McCahan, S., 2001. The effect of dissolving gases or solid in 
water droplets boiling on a hot surface, ASME J. Heat Transfer, 123, 719-728.

Derewnicki, K. P., 1985. Experimental studies of heat transfer and vapour formation in fast transient boiling, Int. J. Heat Mass Transfer 28, 2085-2092.

Eckert, E. R. G. and Drake, R. M. Jr., 1972. Analysis of Heat and Mass Transfer, McGraw-Hill, New York, 158-166.

Fukai, J., Ishizuka, H., Sakai, Y., Kaneda, M., Morita, M. and Takahara, A., 2006. Effects of droplet size and solute concentration on drying process of polymer solution droplets deposited on homogeneous surfaces, Int. J. Heat Mass Transfer 49, 3561-3567.

Fujimoto, H., Shiraishi, H. and Hatta, N., 2000. Evolution of liquid/solid contact area of a drop impinging on a solid surface, Int. J. Heat Mass Transfer 43, 1673-1677.

Fujimoto, H. and Takuda, H., 2004. Entrapment of air at $45^{\circ}$ oblique collision of a water drop with a smooth solid surface at room temperature, Int. J. Heat Mass Transfer $47,3301-3305$.

Furuya, M. and Arai, T., 2008. Effect of surface property of molten metal pools on triggering of vapor explosions in water droplet impingement, Int. J. Heat Mass Transfer $51,4439-4446$.

Glod, S., Poulikakos, D., Zhao, Z. and Yadigaroglu, G., 2002. An investigation of microscale explosive vaporization of water on an ultrathin Pt wire, Int. J. Heat Mass Transfer 45, 367-379.

Han, I.Y. and Kim, S.J., 2008. Diode temperature sensor array for measuring micro-scale surface temperatures with high resolution, Sensors and Actuators A, 141, $52-58$.

Hatta, N., Fujimoto, H., Takuda, H., Kinoshita, K. and Takahashi, O., 1995. Collision Dynamics of a Water Droplet Impinging on a Rigid Surface above the Leidenfrost Temperature, ISIJ Int. 35, 50-55.

Hatta, N., Fujimoto, H., Kinoshita, K. and Takuda, H., 1997. Experimental Study of Deformation Mechanism of a Water Droplet Impinging on Hot Metallic Surfaces above the Leidenfrost Temperature, Trans. ASME, J. Fluids Eng. 119, 692-699.

Hong, Y., Ashgriz, N. and Andrews, J., 2004. Experimental Study of Bubble Dynamics on a Micro Heater Induced by Pulse Heating, ASME J. Heat Transfer 126, 259-271.

Iida, Y., Okuyama, K. and Sakurai, K., 1994. Boiling nucleation on a very small film heater subjected to extremely rapid heating, Int. J. Heat Mass Transfer 37, 2771-2780.

Inada, S. and Yang, W. J., 1993. Mechanisms of miniaturization of sessile drops on a heated surface, Int. J. Heat Mass Transfer 36, 1505-1515.

Kang, B. S. and Lee, D. H., 2000. On the dynamic behavior of a liquid droplet impacting upon an inclined heated surface, Exp. Fluids 29, 380-387. 
Karl, A. and Frohn, A., 2000. Experimental investigation of interaction processes between droplets and hot walls, Phys. Fluids 12, 785-796.

Ko, Y. S. and Chung, S. H., 1996. An experiment on the breakup of impinging droplets on a hot surface, Exp. Fluids 21, 118-123.

Lee, H. S. and Merte, H. Jr., 1996. Spherical vapor bubble growth in uniformly superheated liquid, Int. J. Heat Mass Transfer, 39-12, 2427-2447.

Lienhard, J. H., 1976. Correlation for the limiting liquid superheat, Chem. Eng. Sci. 31, 847-849.

Manzello, S. L. and Yang, J. C., 2002. On the collision dynamics of a water droplet containing an additive on a heated solid surface, Proc. R. Soc. Lond. A 458, 2417-2444.

Mehdi-Nejad, V., Mostaghimi, J. and Chandra, S., 2003. Air bubble entrapment under an impacting droplet, Phys. Fluids 15, 173-183.

Mehdizadeh, N. Z. and Chandra, S., 2006. Boiling during high-velocity impact of water droplets on a hot stainless steel surface, Proc. R. Soc. A 462, 3115-3131.

Moita, A. S. and Moreira, A. L. N., 2007. Drop impacts onto cold and heated rigid surfaces: Morphological comparisons, disintegration limits and secondary atomization, Int. J. Heat Fluid Flow 28, 735-752.

Nagai, N. and Nishio, S., 1996. Leidenfrost Temperature on an Extremely Smooth Surface, Exp. Therm. Fluid Sci. 12, 373-379.

Pasandideh-Fard, M., Qiao, Y. M. and Chandra, S., 1996. Capillary effects during droplet impact on a solid surface, Phys. Fluids 8, 650-659.

Pedersen, C.O., 1970. An experimental study of the dynamic behavior and heat transfer characteristics of water droplets impinging on a heated surface, Int. J. Heat Mass Transfer, 13, 369-381.

Rein, M., 1993. Phenomena of liquid drop impact on solid and liquid surfaces, Fluid Dyn. Res. 12, 61-93.

Rein, M., 2002. Interactions between drops and hot surfaces, In Drop-Surface Interactions. CISM Courses and Lectures no. 456, Springer-Verlag Wien New York, , 185-217.

Seki, M., Kawamura, H. and Sanokawa, K., 1978. Transient temperature profile of a hot wall due to an impinging liquid jet, ASME J. Heat Transfer, 100, 167-169.

Skripov, V. P., 1974. Metastable Liquids, John Wiley and Sons, New York, 83-177.

Tartarini, P., Corticelli,M.A., and Tarozzi, L., 2009. Dropwise cooling: Experimental tests by infrared thermography and numerical simulations, Applied thermal Engg., 29, 1391-1397.

Thomas, O. C., Cavicchi, R. E. and Tarlov, M. J., 2003. Effect of surface wettability on fast transient microboiling behavior, Langmuir 19, 6168-6177. 
Thoroddsen, S. T. , Etoh, T. G. and Takehara, K., 2003. Air entrapment under an impacting drop, J. Fluid Mech. 478, 125-134.

Thoroddsen, S. T., Etoh, T. G. and Takehara, K., Ootsuka, N. and Hatsuki, Y., 2005. The air bubble entrapped under a drop impacting on a solid surface", J. Fluid Mech. 545, 203-212.

Ueda, T., Enomoto, T. and Kanetsuki, M., 1979. Heat Transfer Characteristics and Dynamic Behavior of Saturated Droplets Impinging on a Heated Vertical Surface, Bull. JSME 22, 724-732.

Wang, G. and Cheng, P., 2009. Subcooled flow boiling and microbubble emission boiling phenomena in a partially heated microchannel, Int. J. Heat Mass Transfer 52, 79-91.

Wachters, L. H. J. and Westerling, N. A. J., 1966. The heat transfer from a hot wall to impinging water drops in the spheroidal state, Chem. Eng. Sci. 21, 1047-1056.

Xiong, T. Y. and Yuen, M. C., 1991. Evaporation of a liquid droplet on a hot plate, Int. J. Heat Mass Transfer 34, 1881-1894.

Yarin, A. L., 2006. Drop Impact Dynamics: Splashing, Spreading, Receding, Bouncing..., Ann. Rev. Fluid Mech. 38, 159-192.

57 papers are referenced. 


\section{List of figure and table captions}

Figure 1: Schematic diagram of experimental apparatus.

Figure 2: Schematic diagram of photography setup.

Figure 3: Samples of double-exposed images of water droplet impinging on heated Inconel alloy 625 surface for $\left(d_{p}, v, T_{w}\right)=\left(0.58 \mathrm{~mm}, 2.1 \mathrm{~m} / \mathrm{s}, 500{ }^{\circ} \mathrm{C}\right)$.

Figure 4: Impact of water droplet on Inconel alloy 625 surface for $\left(d_{p}, v, T_{w}\right)=(0.60$ $\mathrm{mm}, 2.1 \mathrm{~m} / \mathrm{s}, 170{ }^{\circ} \mathrm{C}$ ): (a) side-view images and (b) bird's-eye-view images.

Figure 5: Impact of water droplet on Inconel alloy 625 surface for $\left(d_{p}, v, T_{w}\right)=(0.56$ $\left.\mathrm{mm}, 1.8 \mathrm{~m} / \mathrm{s}, 200^{\circ} \mathrm{C}\right)$.

Figure 6: Impact of a water droplet on Inconel alloy 625 surface for $\left(d_{p}, v, T_{w}\right)=$ $\left(0.57 \mathrm{~mm}, 1.7 \mathrm{~m} / \mathrm{s}, 200{ }^{\circ} \mathrm{C}\right)$.

Figure 7: Impact of water droplet on solid surface for $\left(d_{p}, v, T_{w}\right)=(0.58 \mathrm{~mm}, 2.1 \mathrm{~m} / \mathrm{s}$, $\left.300{ }^{\circ} \mathrm{C}\right)$.

Figure 8: Impact of water droplet on solid surface for $\left(d_{p}, v, T_{w}\right)=(0.57 \mathrm{~mm}, 1.9 \mathrm{~m} / \mathrm{s}$, $\left.400{ }^{\circ} \mathrm{C}\right)$.

Figure 9: Collision of a droplet with hot solid for $\left(d_{p}, v, T_{w}\right)=(0.58 \mathrm{~mm}, 2.0 \mathrm{~m} / \mathrm{s}$, $\left.500{ }^{\circ} \mathrm{C}\right)$.

Figure 10: Collision of droplet with hot solid for $\left(d_{p}, v, T_{w}\right)=(0.54 \mathrm{~mm}, 3.0 \mathrm{~m} / \mathrm{s}$, $\left.400^{\circ} \mathrm{C}\right)$.

Figure 11: Collision of droplet with hot solid for $\left(d_{p}, v, T_{w}\right)=(0.53 \mathrm{~mm}, 3.2 \mathrm{~m} / \mathrm{s}$, $\left.500^{\circ} \mathrm{C}\right)$.

Figure 12: Collision of droplet with hot solid for $\left(d_{p}, v, T_{w}\right)=(0.57 \mathrm{~mm}, 4.1 \mathrm{~m} / \mathrm{s}$, $\left.500{ }^{\circ} \mathrm{C}\right)$.

Figure 13: Impact of water droplet on Inconel alloy 625 surface for $\left(d_{p}, v, T_{w}\right)=$ $\left(2.51 \mathrm{~mm}, 1.00 \mathrm{~m} / \mathrm{s}, 170{ }^{\circ} \mathrm{C}\right)$.

Figure 14: Impact of water droplet on Inconel alloy 625 surface for $\left(d_{p}, v, T_{w}\right)=$ $\left(2.50 \mathrm{~mm}, 0.87 \mathrm{~m} / \mathrm{s}, 200^{\circ} \mathrm{C}\right)$.

Figure 15: Impact of water droplet on Inconel alloy 625 surface for $\left(d_{p}, v, T_{w}\right)=$ $\left(2.50 \mathrm{~mm}, 1.01 \mathrm{~m} / \mathrm{s}, 300^{\circ} \mathrm{C}\right)$.

Figure 16: Impact of water droplet on Inconel alloy 625 surface for $\left(d_{p}, v, T_{w}\right)=$ 
(2.42 mm, $\left.0.90 \mathrm{~m} / \mathrm{s}, 400{ }^{\circ} \mathrm{C}\right)$.

Figure 17: Impact of water droplet on Inconel alloy 625 surface for $\left(d_{p}, v, T_{w}\right)=$ $\left(2.50 \mathrm{~mm}, 1.00 \mathrm{~m} / \mathrm{s}, 500{ }^{\circ} \mathrm{C}\right)$.

Figure 18: Time histories of spreading diameter of droplet for (a) $T_{w}=170{ }^{\circ} \mathrm{C}$ and (b) $T_{w}=500{ }^{\circ} \mathrm{C}$, and (c) definition of dimensionless diameter.

Figure 19: Impact of water droplet on Inconel alloy 625 surface for $\left(d_{p}, v, T_{w}\right)=$ $\left(2.47 \mathrm{~mm}, 1.40 \mathrm{~m} / \mathrm{s}, 400{ }^{\circ} \mathrm{C}\right)$.

Figure 20: Impact of water droplet on Inconel alloy 625 surface for $\left(d_{p}, v, T_{w}\right)=$ $\left(2.59 \mathrm{~mm}, 1.48 \mathrm{~m} / \mathrm{s}, 500{ }^{\circ} \mathrm{C}\right)$.

Figure 21: Impact of water droplet on Inconel alloy 625 surface with diamond particles for $\left(d_{p}, v, T_{w}\right)=\left(2.57 \mathrm{~mm}, 1.06 \mathrm{~m} / \mathrm{s}, 170^{\circ} \mathrm{C}\right)$. 
Droplets
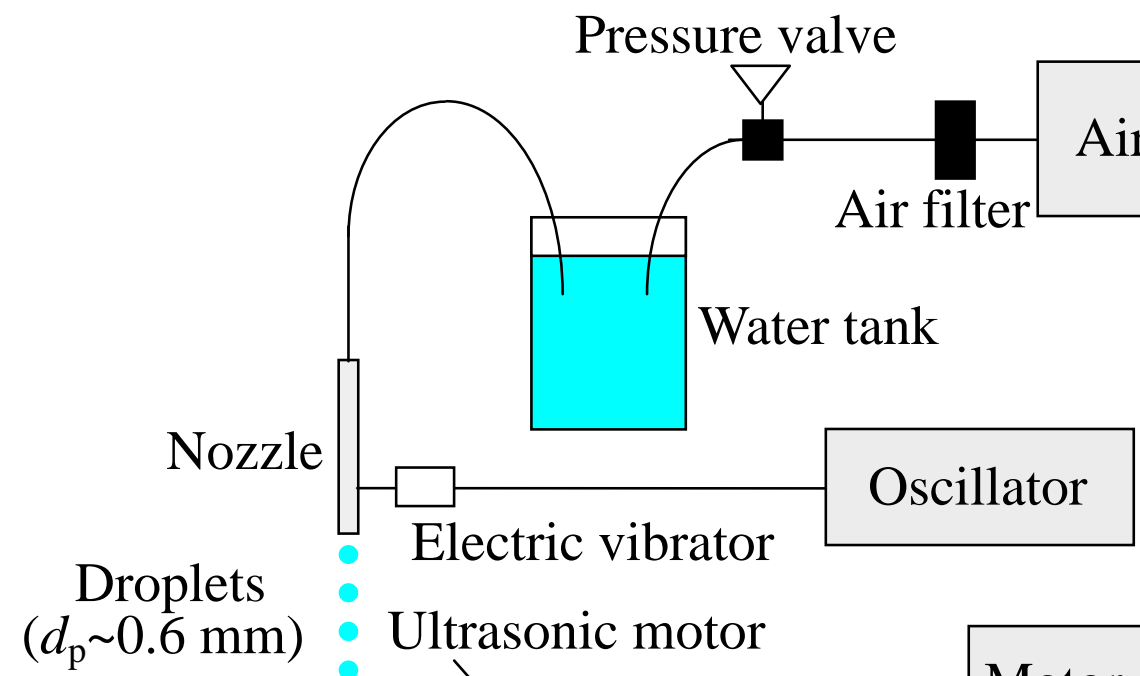

- Ultrasonic motor

Slit hole

Motor controller

Camera B Rotating disk

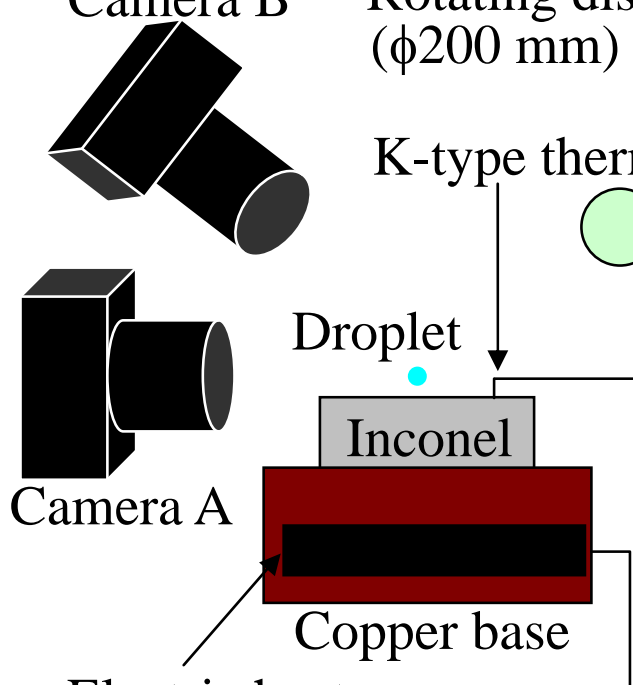

Electric heater

Temperature controller

Fig.1 


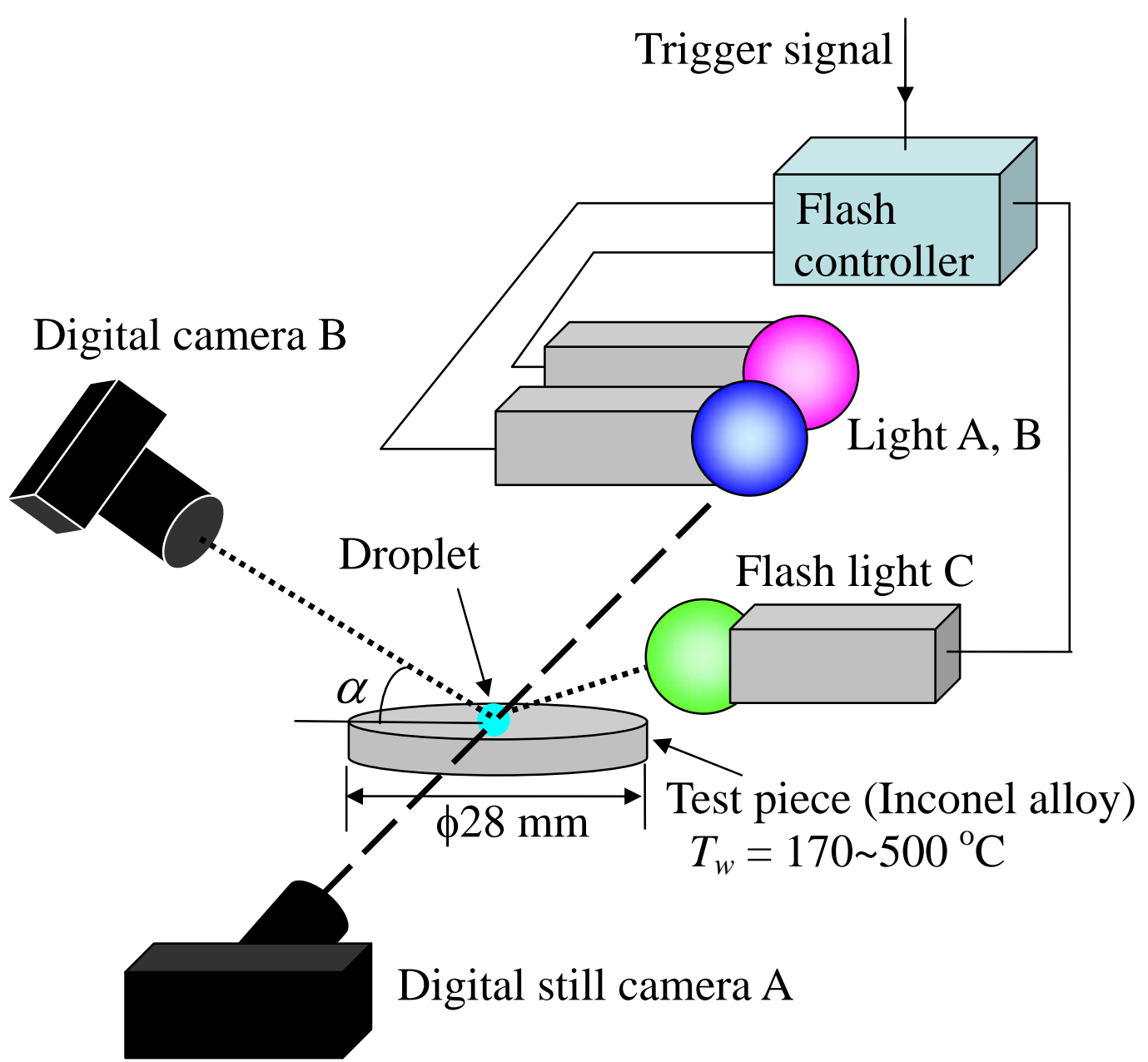

Fig. 2 
(a)

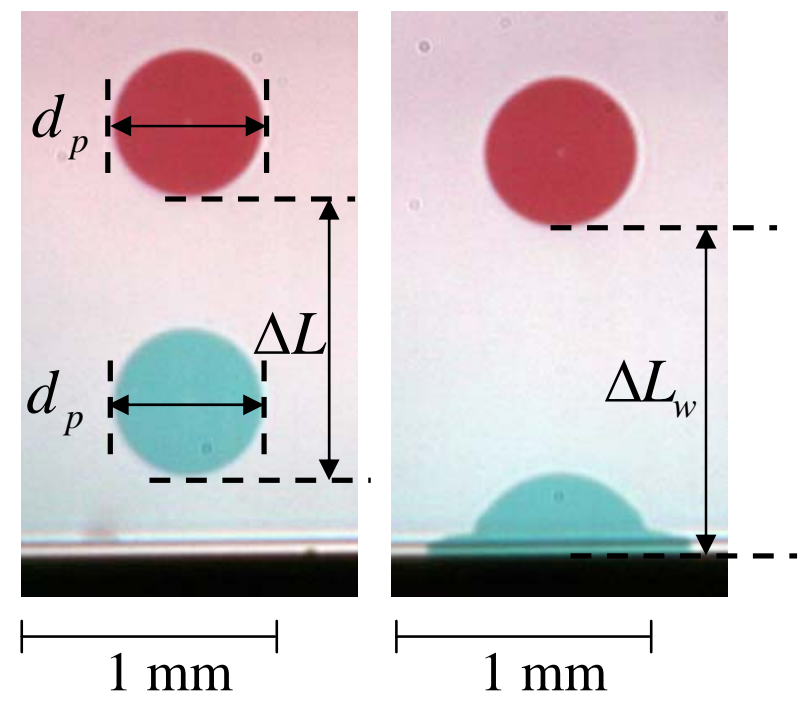

(b)

Fig. 3 


\section{A Self-archived copy in}

京都大学

$t_{e}$ YYOTO UNIVERSITYS

$(\tau=0.15)$

\section{$0.59 \mathrm{~ms}(2.06)$}

$0.84 \mathrm{~ms}(2.97)$

$0.10 \mathrm{~ms}$

(0.36)

$0.99 \mathrm{~ms}(3.47)$

$0.19 \mathrm{~ms}(0.68)$

$1.37 \mathrm{~ms}$ 
(2) 京都大学 $(0.15)$

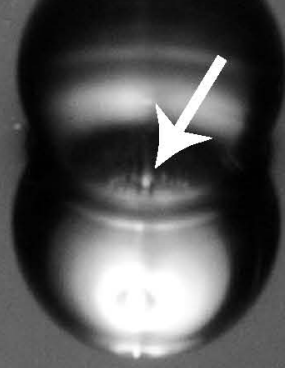

$0.10 \mathrm{~ms}$ (0.36)

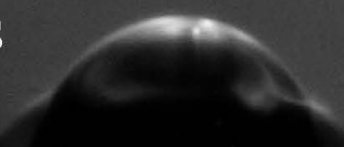

$0.19 \mathrm{~ms}$ (0.68)
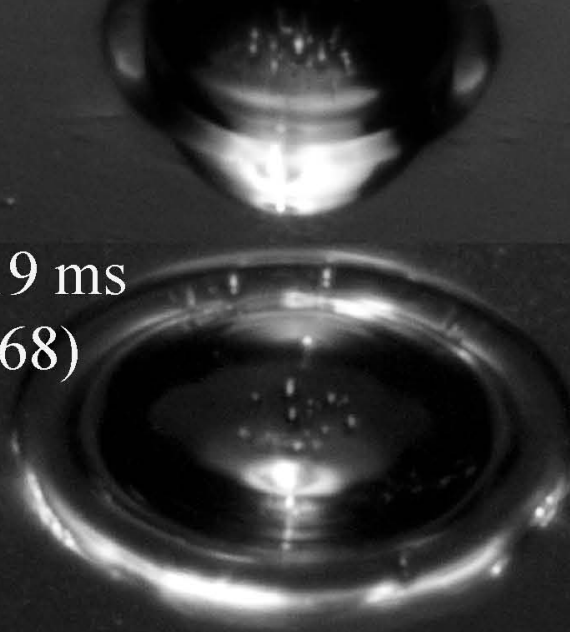

$0.33 \mathrm{~ms}$

(1.17)

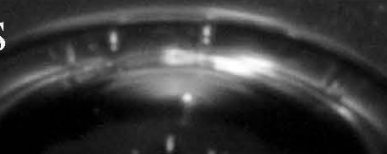

2

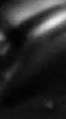

Y.

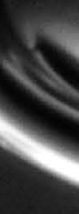

$0.47 \mathrm{~ms}$

(

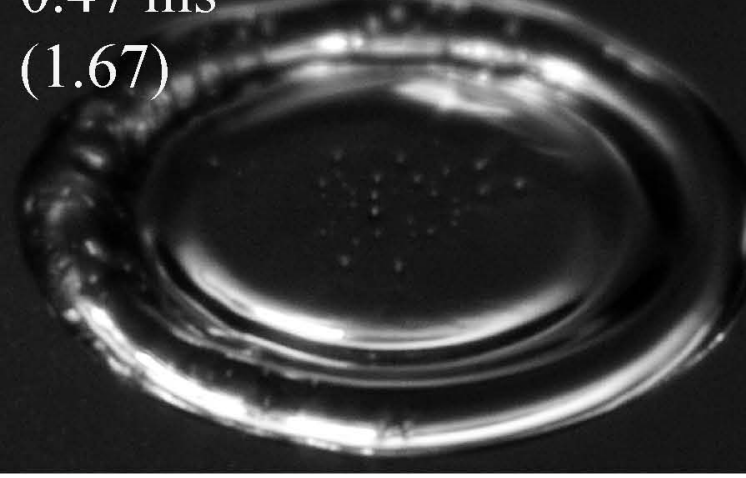

$0.59 \mathrm{~ms}$

(2.06) KURENAIII

$0.84 \mathrm{~ms}$

(2.97)

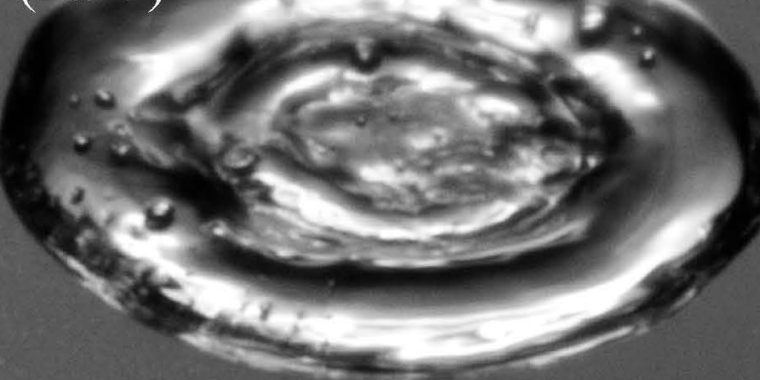

$0.99 \mathrm{~ms}$

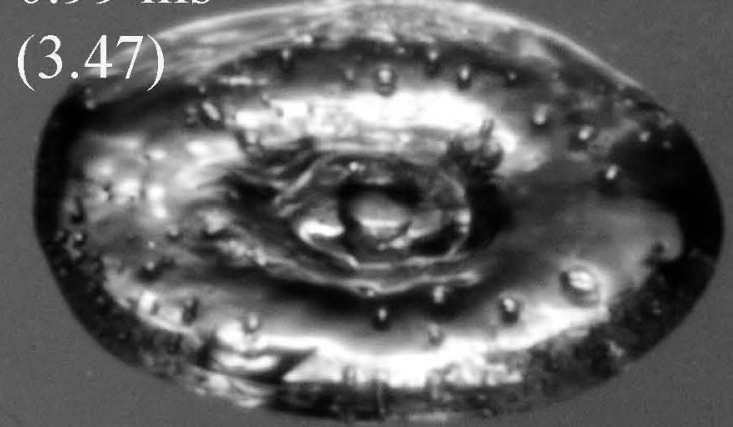

$1.37 \mathrm{~ms}$

$(4.80) \geq 8$,
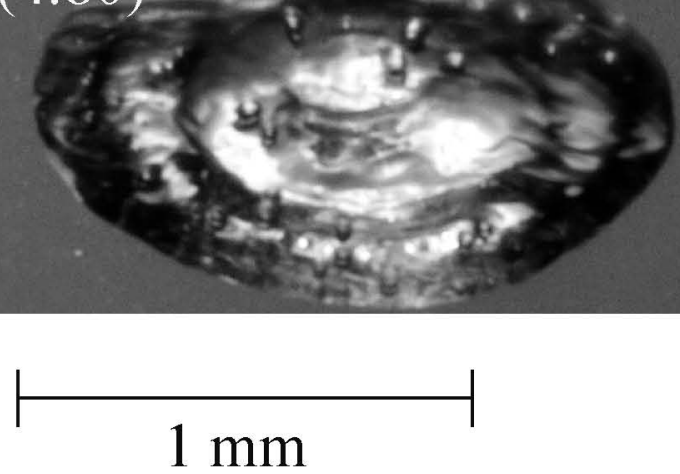

Fig.4(b) 
(2) 京都大学 (0.23)

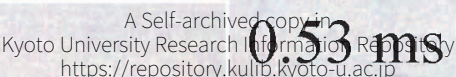

$$
\text { (1.72) }
$$

$0.12 \mathrm{~ms}$

$(0.40)$
$0.17 \mathrm{~ms}$

$(0.57)$
$0.26 \mathrm{~ms}$

$(0.83)$

$0.39 \mathrm{~ms}$

(1.28)
$1.17 \mathrm{~ms}$

(3.83)
$1.94 \mathrm{~ms}$

(6.34)
$2.93 \mathrm{~ms}$

(9.60)

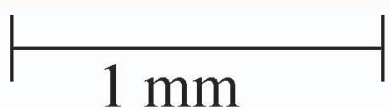

Fig.5a 


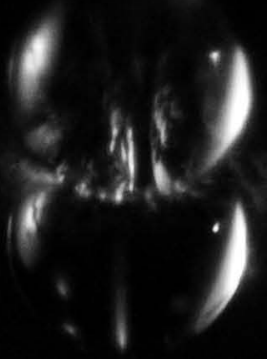

$0.07 \mathrm{~ms}$

$0.19 \mathrm{~ms}$
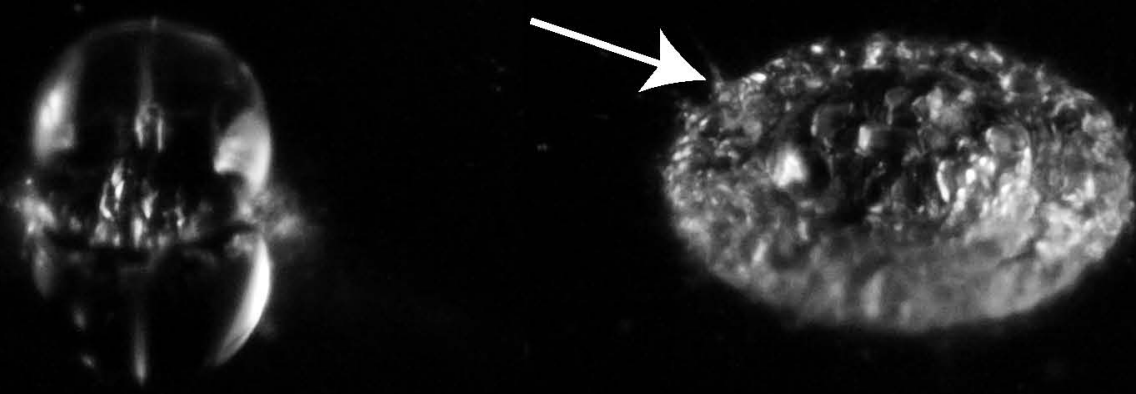

$0.11 \mathrm{~ms}$
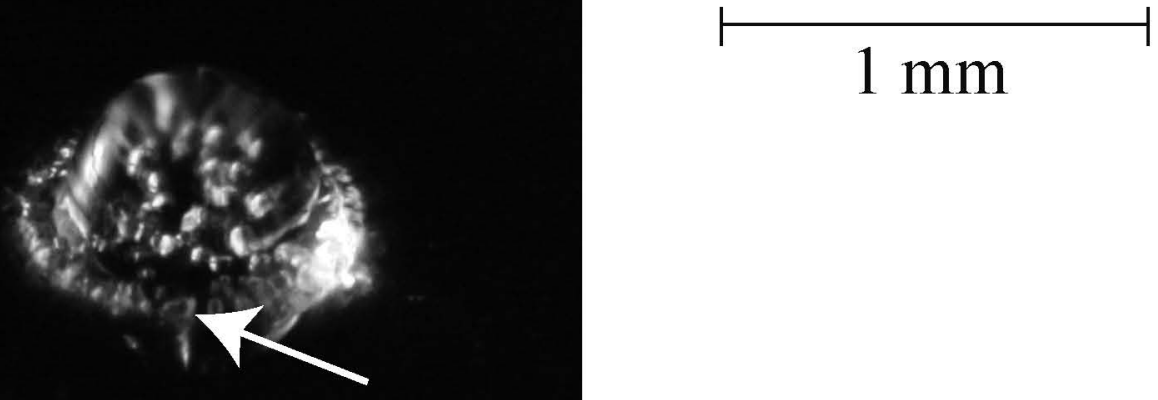

Fig. 6 


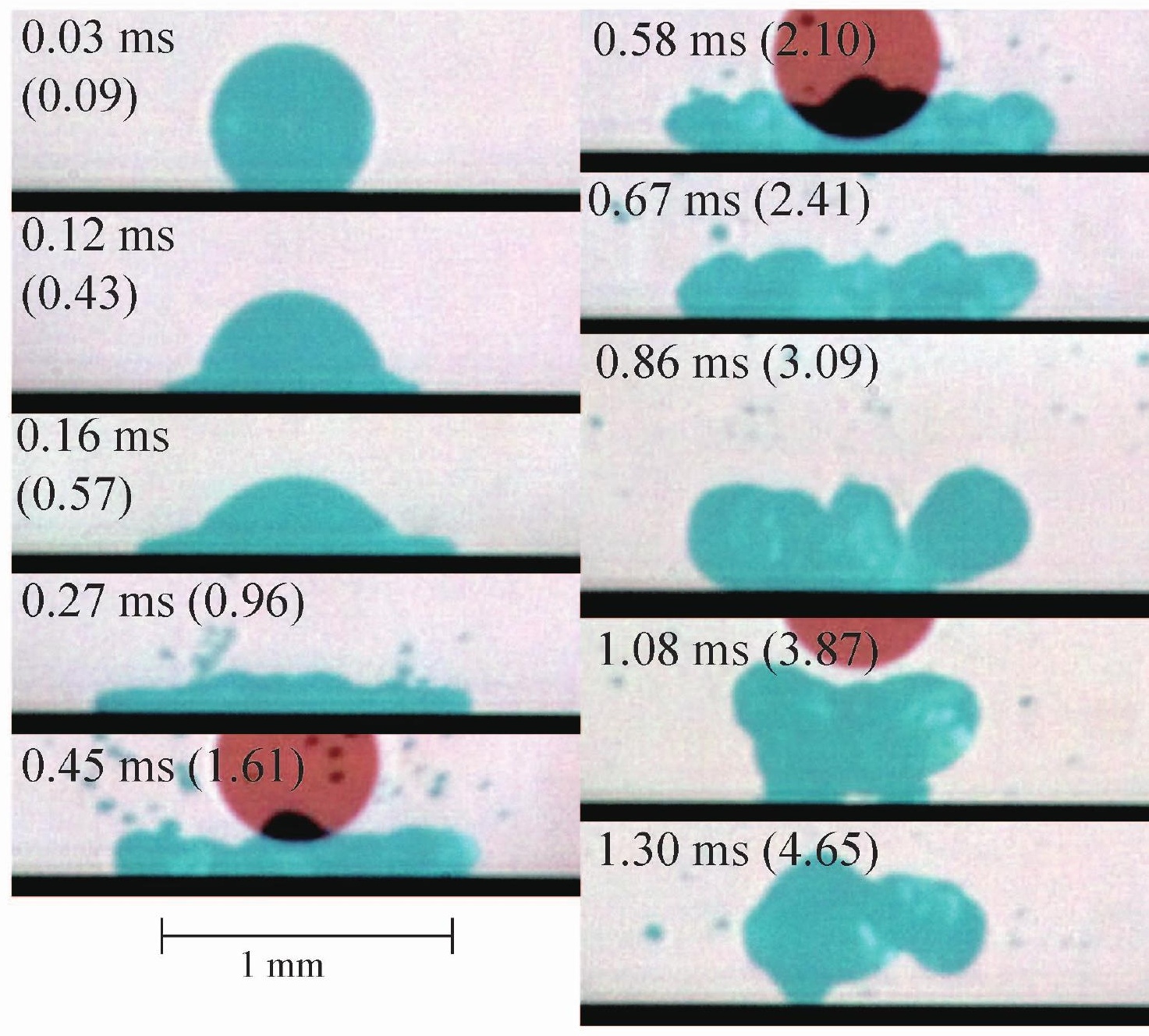

Fig. 7a 
$0.12 \mathrm{~ms}(0.43)$
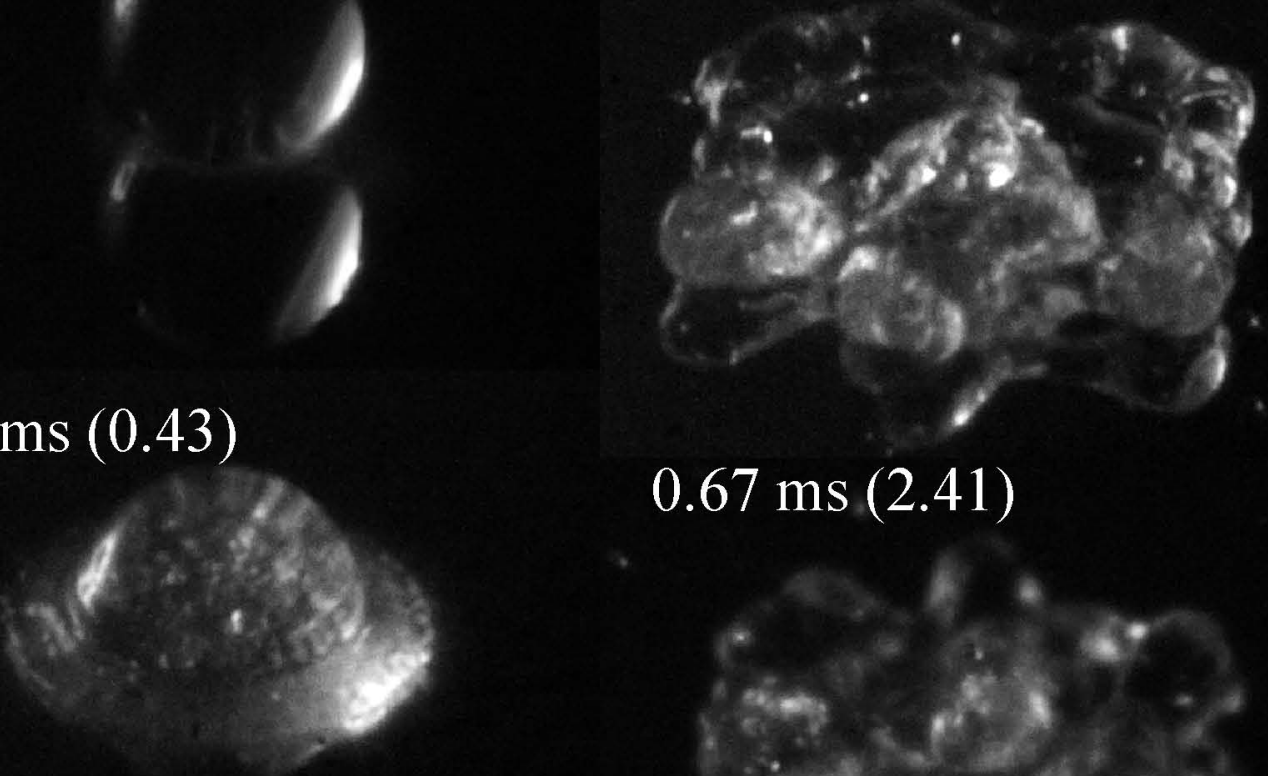

$0.16 \mathrm{~ms}(0.57)$

$0.67 \mathrm{~ms}(2.41)$

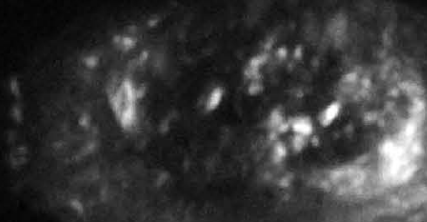

$0.27 \mathrm{~ms}(0.96)$

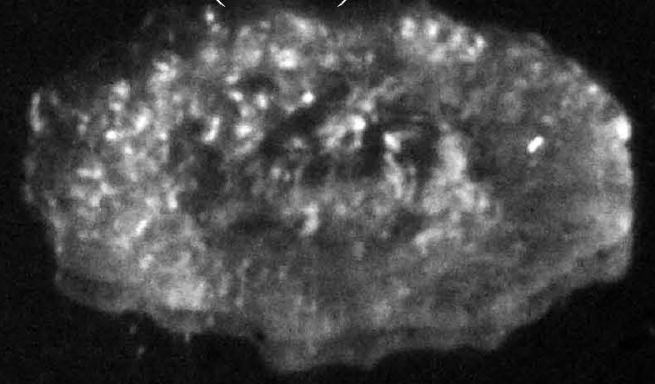

$0.45 \mathrm{~ms}(1.61)$
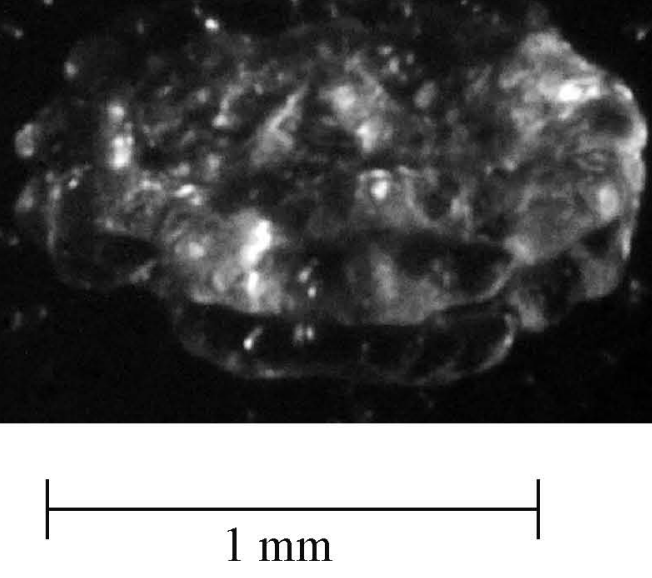

Fig. $7 b$

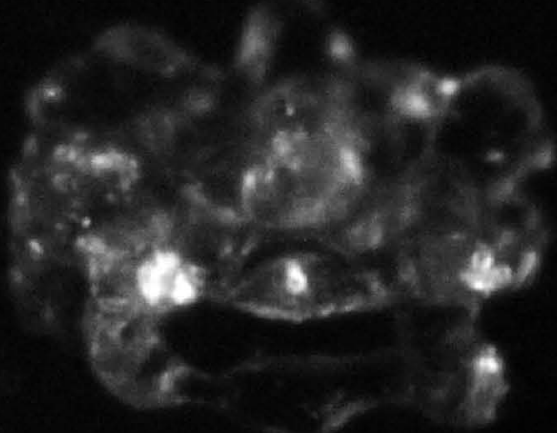

$0.86 \mathrm{~ms}(3.09)$

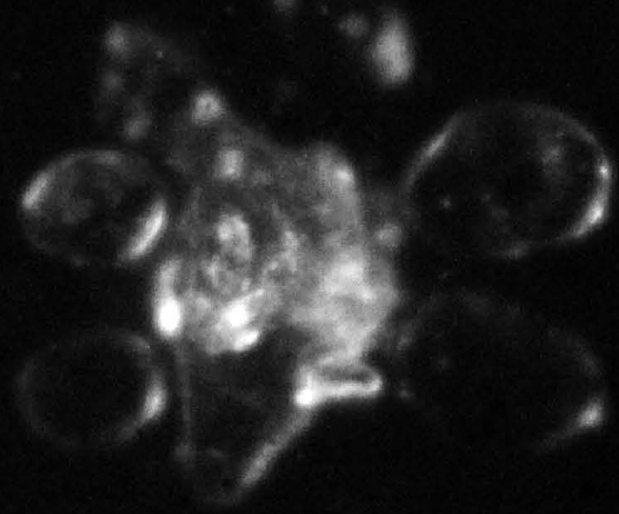

$1.08 \mathrm{~ms}(3.87)$

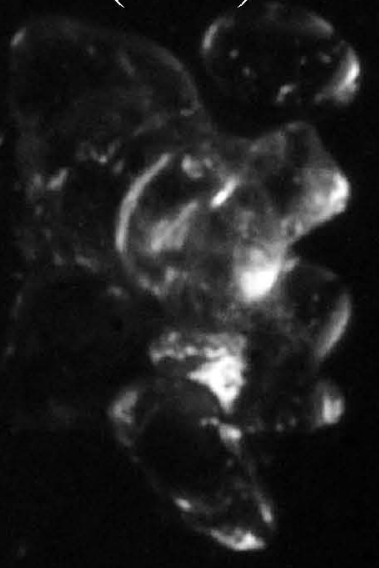

$1.30 \mathrm{~ms}(4.65)$

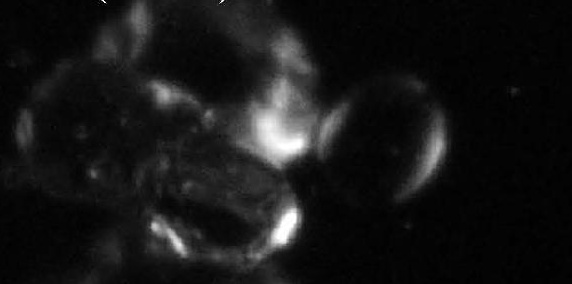




\section{$0.68 \mathrm{~ms}$}

(2.29)

$0.17 \mathrm{~ms}(0.57)$

$0.74 \mathrm{~ms}$

(2.49)

$0.22 \mathrm{~ms}(0.75)$ 
京橥大爱 $\mathrm{ms}(0.34)$

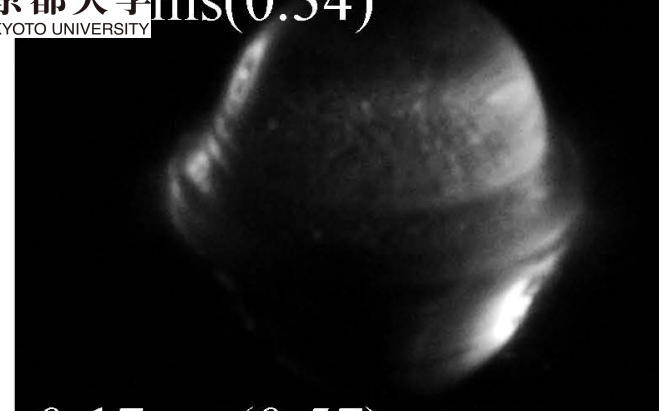

$0.17 \mathrm{~ms}(0.57)$

$0.22 \mathrm{~ms}(0.75)$

$0.30 \mathrm{~ms}(1.01)$

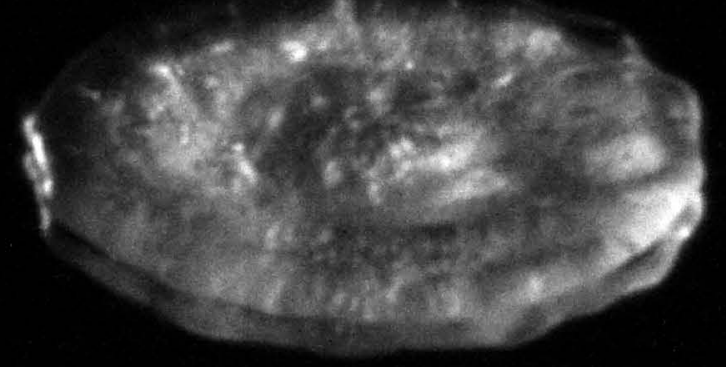

$0.42 \mathrm{~ms}(1.43)$

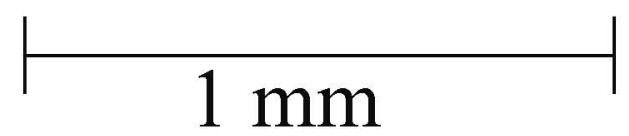

$0.55 \mathrm{~ms}(1.86) \quad$ KURENAI II

$0.68 \mathrm{~ms}(2.29),:$

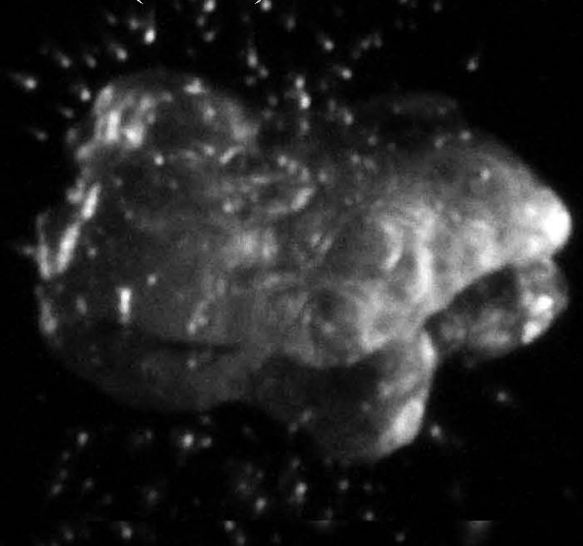

$0.74 \mathrm{~ms}(2.49)$ ".

$$
1.42 \mathrm{~ms}(4.78)
$$

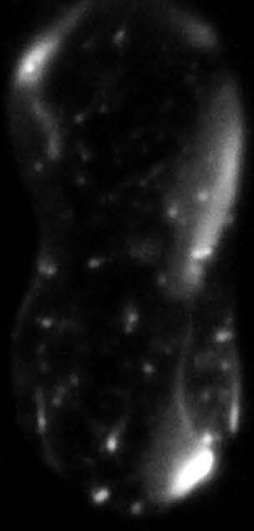

Fig. $8 \mathrm{~b}$ 
(6)京都大学

$0.14 \mathrm{~ms} \quad(0.51)$

$0.32 \mathrm{~ms} \quad(1.14)$

$0.43 \mathrm{~ms} \quad(1.52)$

$0.63 \mathrm{~ms} \quad(2.22)$

$0.79 \mathrm{~ms} \quad(2.79)$

$0.89 \mathrm{~ms}$

(3.13)

\section{$1.58 \mathrm{~ms}$ \\ $(5.57)$}

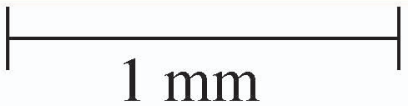

Fig.9a 


\section{$0.13 \mathrm{~ms}(0.72)$}

$0.19 \mathrm{~ms}(1.09)$

$0.27 \mathrm{~ms}$

(1.49)
(3.83)

$(5.10)$

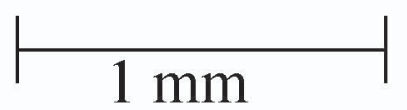

$$
0.91 \mathrm{~ms}
$$

Fig.10a 
$0.08 \mathrm{~ms}$
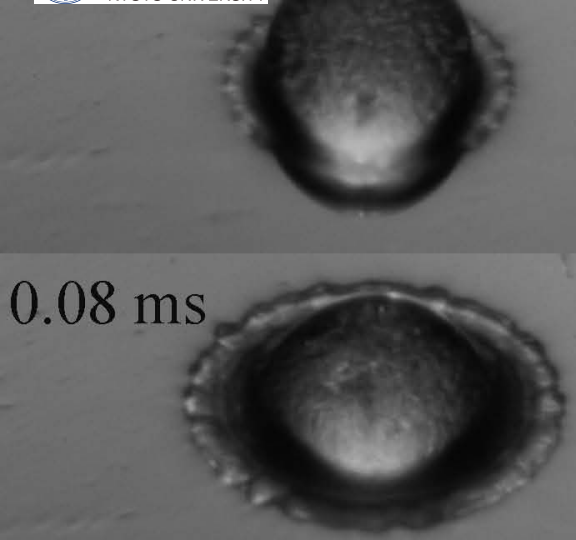

$0.13 \mathrm{~ms}$

(0.44)

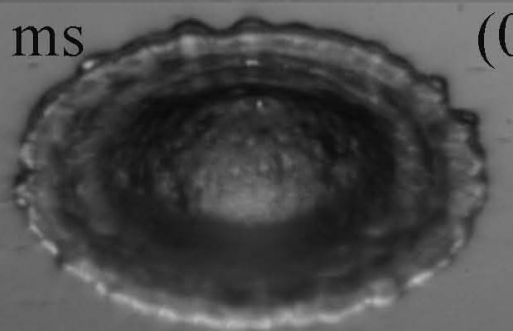

0.1

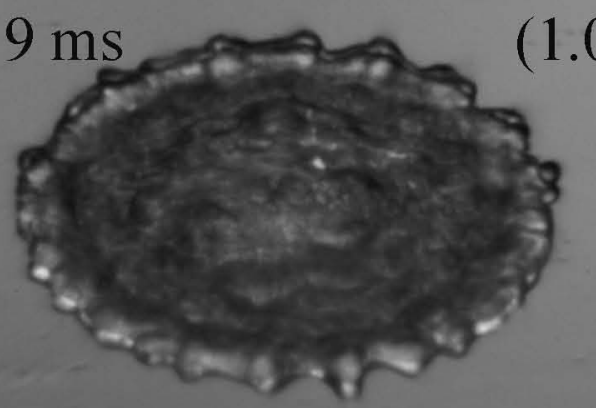

0.2

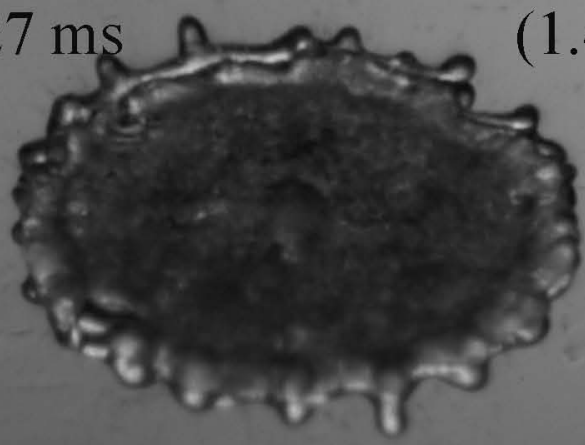

\section{$0.35 \mathrm{~ms}$}

(1.96)

$0.91 \mathrm{~ms}$

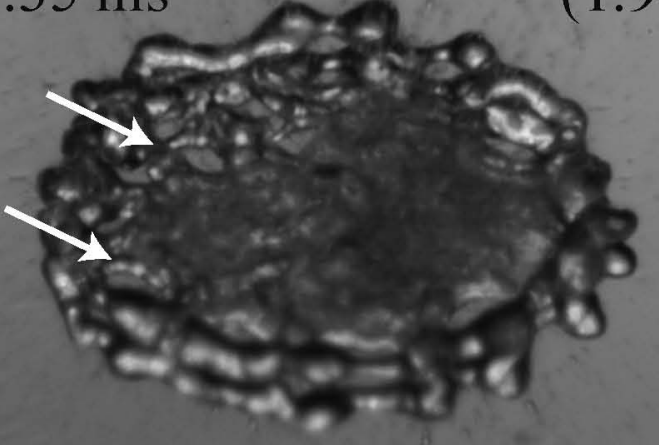

$1 \mathrm{~mm}$

$0.68 \mathrm{~ms}$

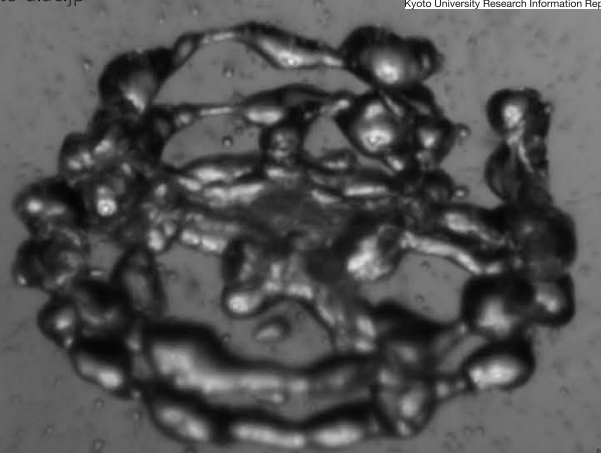

(3.02)

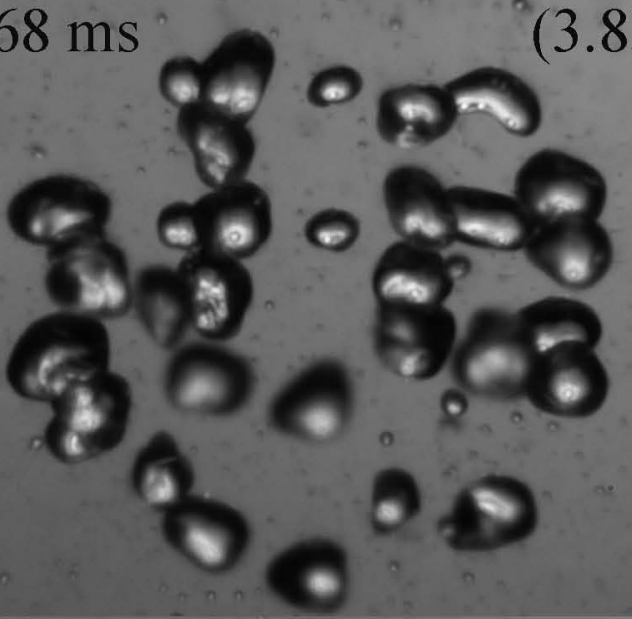

$(5.10)$

$\circ$

6.
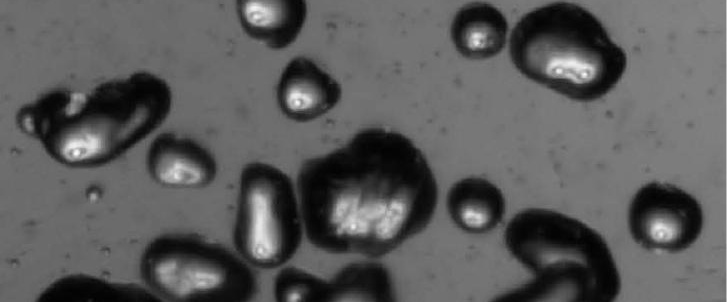

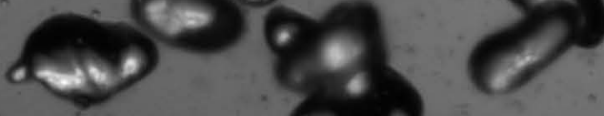

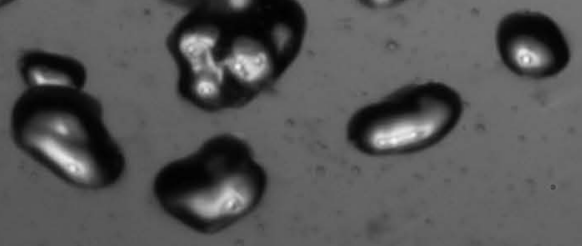

Fig. 10b 
每京都大学

KYOTO UNIVERSITY

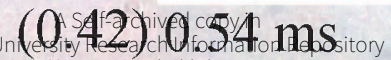
https://repository.kulib.kyoto-u.ac.jp

\section{$0.10 \mathrm{~ms}$}

\section{(0.60) $0.61 \mathrm{~ms}$}

(3.68)

$0.15 \mathrm{~ms}$

(0.91) $0.75 \mathrm{~ms}$

$(4.56)$

$0.23 \mathrm{~ms}$

(1.41)

$0.31 \mathrm{~ms}$

(1.90) $1.08 \mathrm{~ms}$

(6.56)

$0.45 \mathrm{~ms}$

(2.76)

\section{$1 \mathrm{~mm}$}

Fig.11a 
$0.10 \mathrm{~ms}$

(0.60) $\quad 0.54 \mathrm{~ms}$

(3.28)

$0.15 \mathrm{~ms}$

(0.91) $\quad 0.61 \mathrm{~ms}$

$0.23 \mathrm{~ms}$

(1.41)
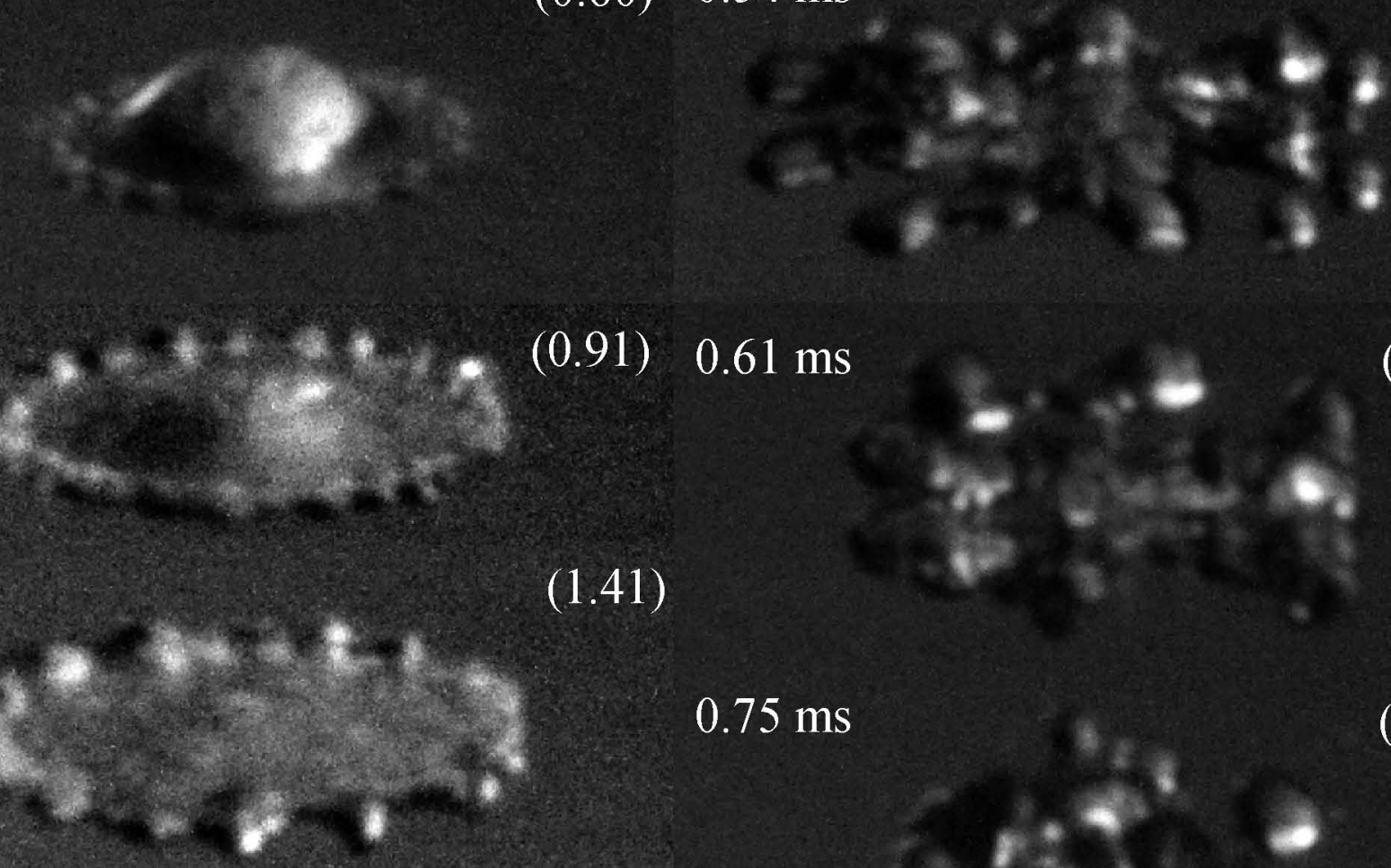

$0.75 \mathrm{~ms}$

$0.31 \mathrm{~ms}$

(1.90)

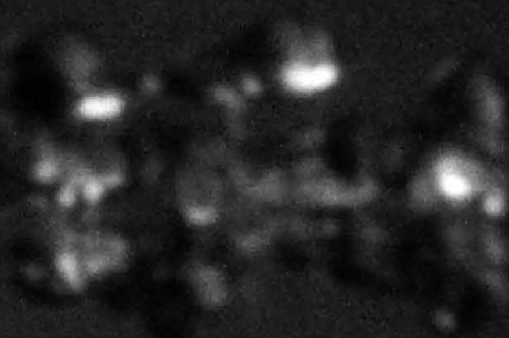

(3.68)

(4.56)

$1.08 \mathrm{~ms}$

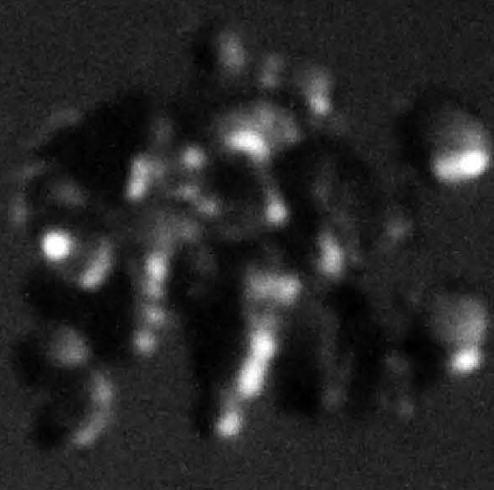

(6.56)

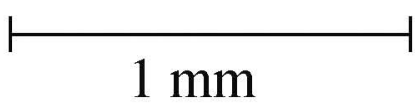

Fig. 11b 


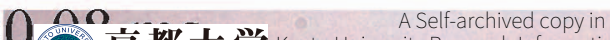

(5) Kyoto University Research Information Repository KYOTO UNIVERSITY https://repository.kulib.kyoto-u.ac.jp

$0.37 \mathrm{~ms}$

$0.50 \mathrm{~ms}$

$0.71 \mathrm{~ms}$

$1.01 \mathrm{~ms}$

$1 \mathrm{~mm}$

Fig. 12 
$0.26 \mathrm{~ms}$

$0.37 \mathrm{~ms}$

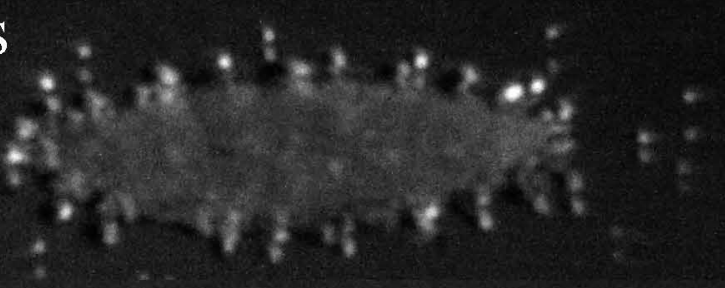

$0.50 \mathrm{~ms}$

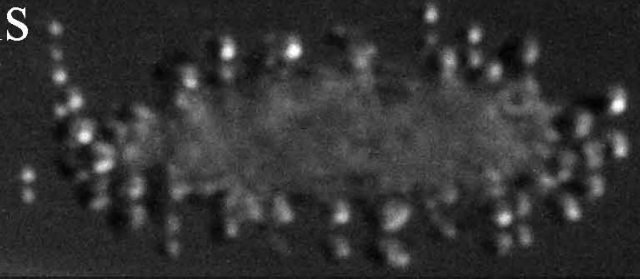

$0.71 \mathrm{~ms}$

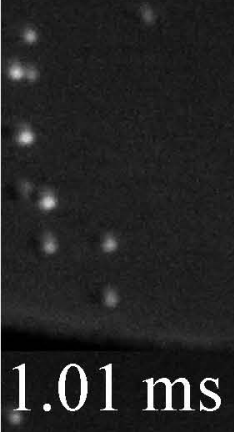

\section{$1 \mathrm{~mm}$}
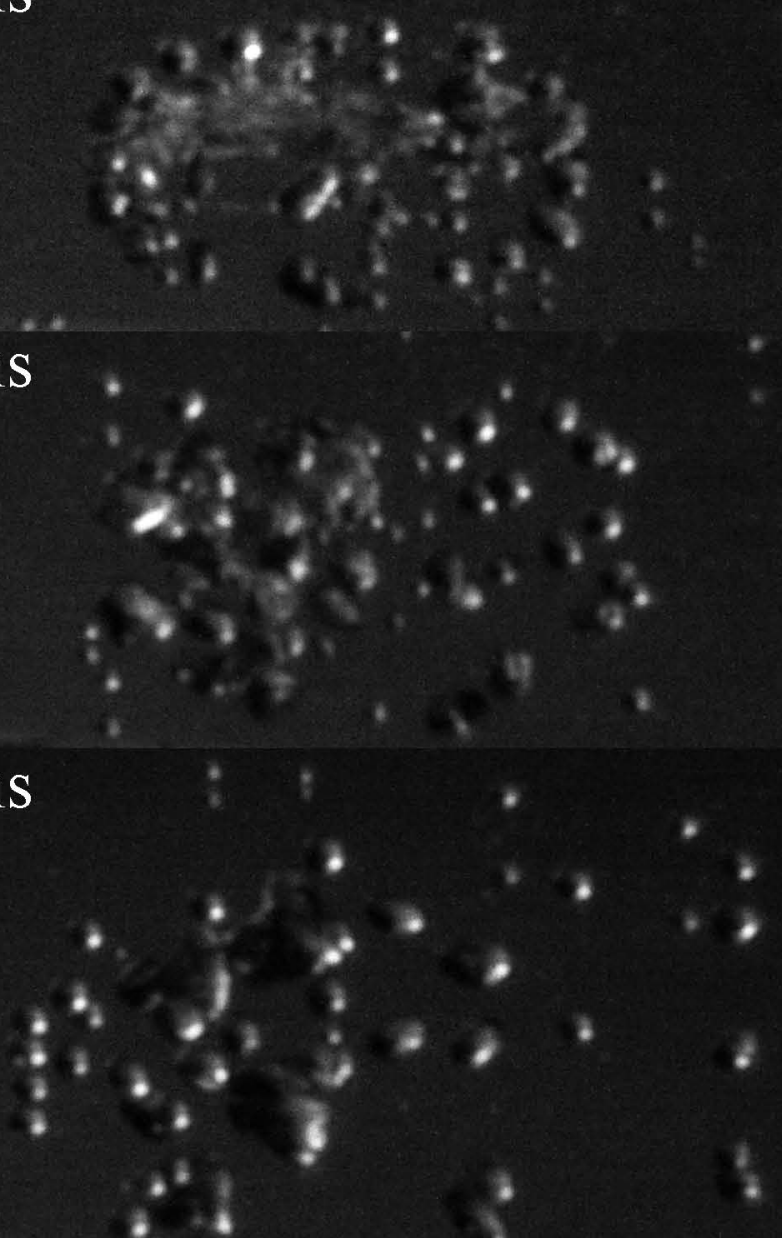

Fig. 12(b) 
$(2$ 京橥大学 29$)=$

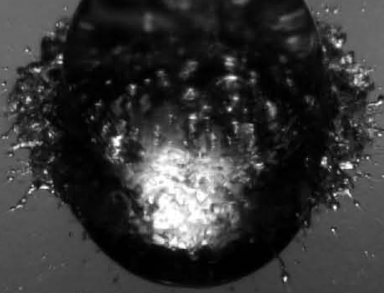

$1.13 \mathrm{~ms} \mathrm{(0.39)}$

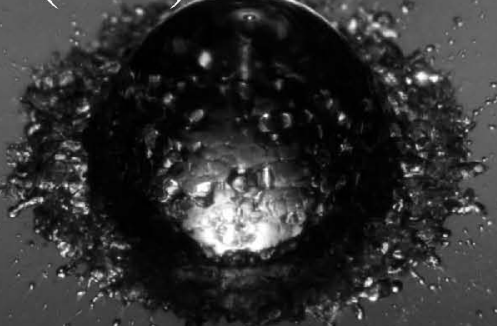

$1.60 \mathrm{~ms}(0.56)$

$2.28 \mathrm{~ms}(0: 80)$

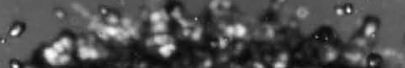

$2 x^{2}-2 x$

$4^{3} \cos ^{2}$

$-7+4 \div 3$ ?

$a+n=2$

$3.67 \mathrm{~ms}(128)$ is

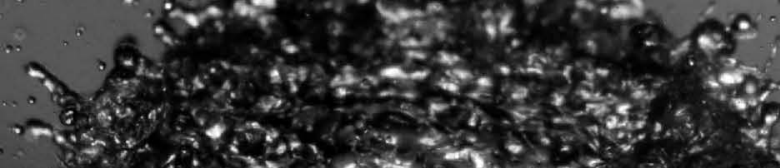

$307 \times 2,18$

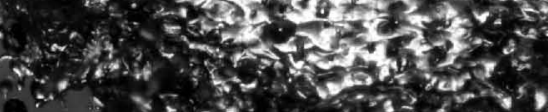

$3 \times x^{2}+2$
$490 \mathrm{~ms} /(-71)$

a o lo $30^{\circ}$ 4. $x^{2}+x^{2}$

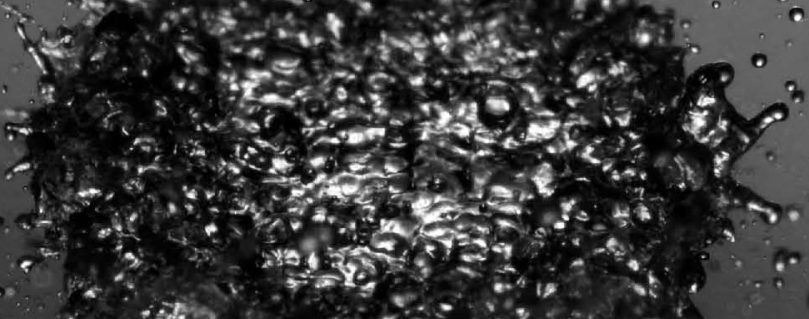

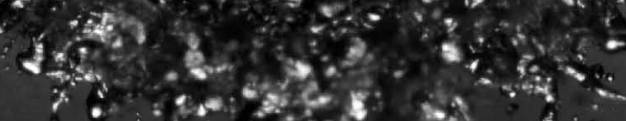

$11.15 \mathrm{~ms}(3.90)$

$0^{\circ} \therefore 80^{\circ}$

a gen 8.5 an ine a ay

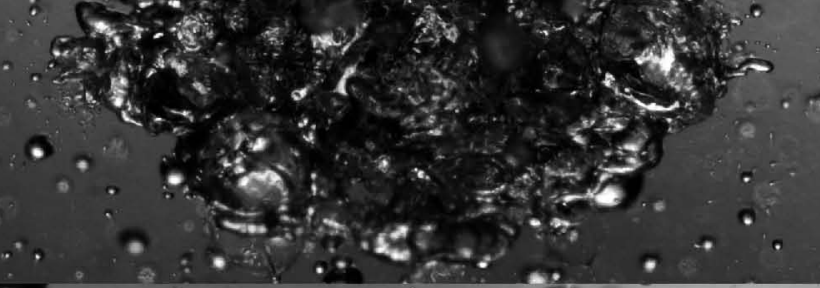

$98.14 \mathrm{~ms}(6.35)$

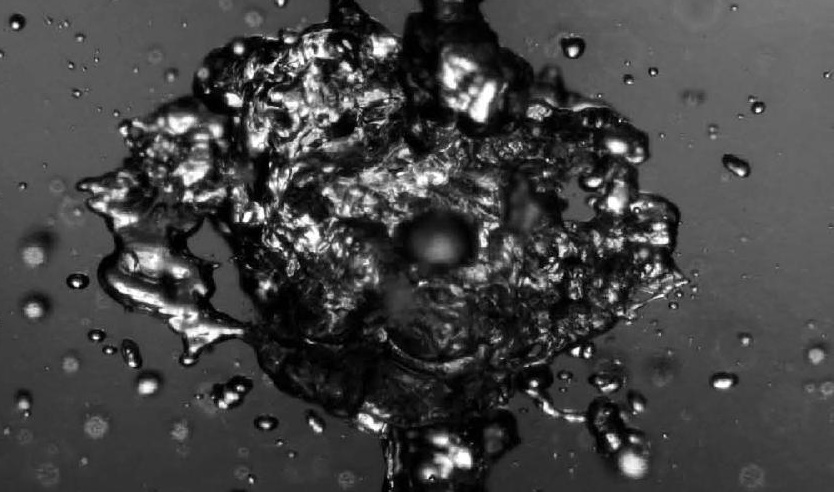

$27.14 \mathrm{~ms}(9.50)$
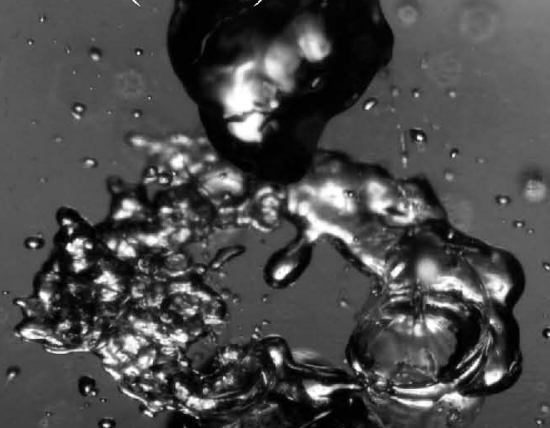

Fig.14 


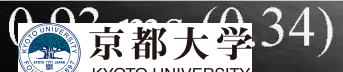

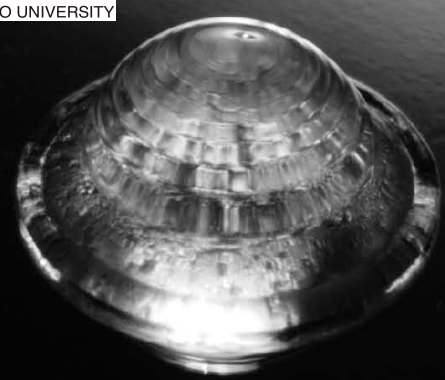

$1.54 \mathrm{~ms}(0.57)$

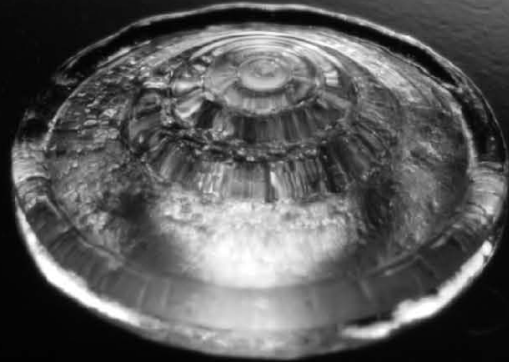

$1.98 \mathrm{~ms}(0.73)$

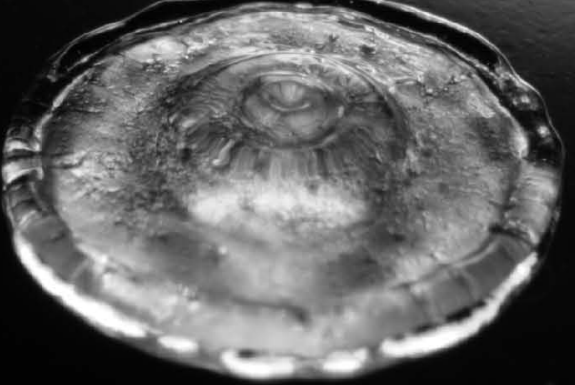

$2.73 \mathrm{~ms}$

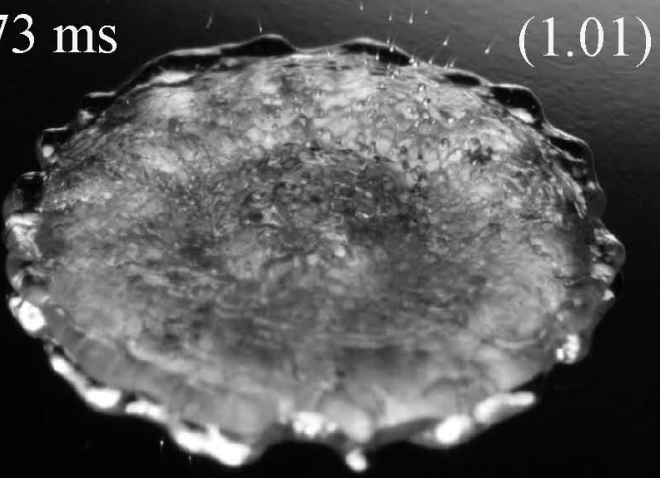

$3.87 \mathrm{~ms}$ (1.43)

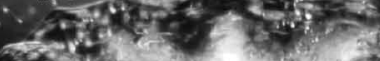
are $y$.

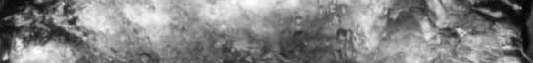

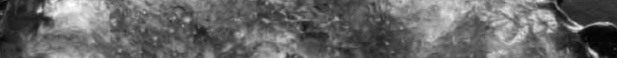

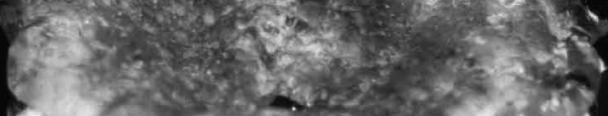

$5.03 \mathrm{~ms} \quad$ KUNRENAI II

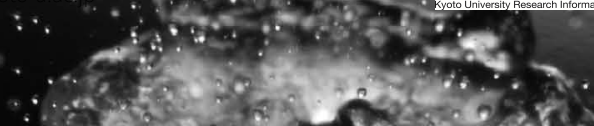

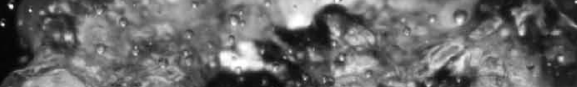

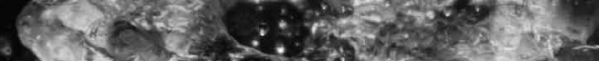

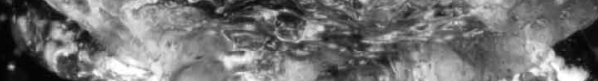
(5)

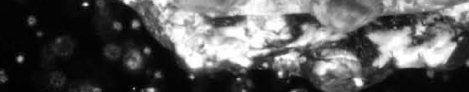
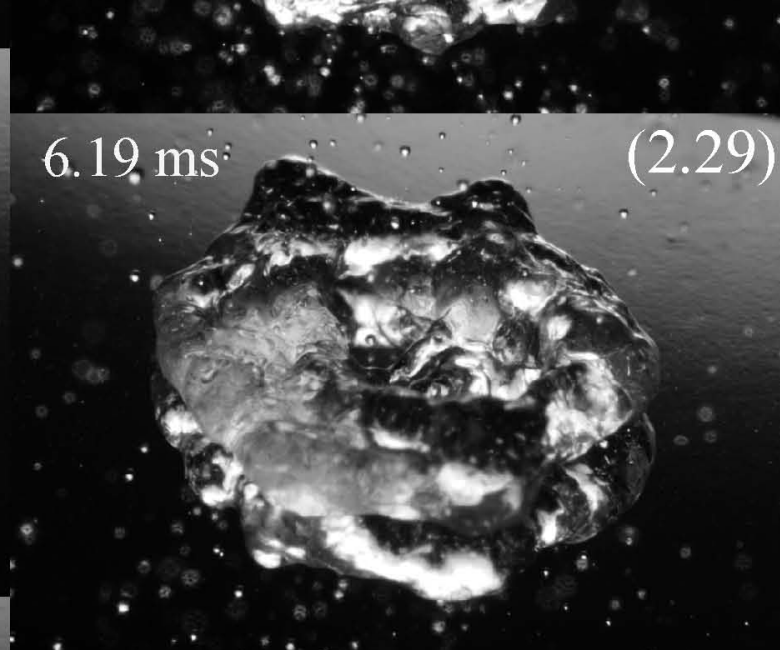

$6.73 \mathrm{~ms}+\mathrm{m}$

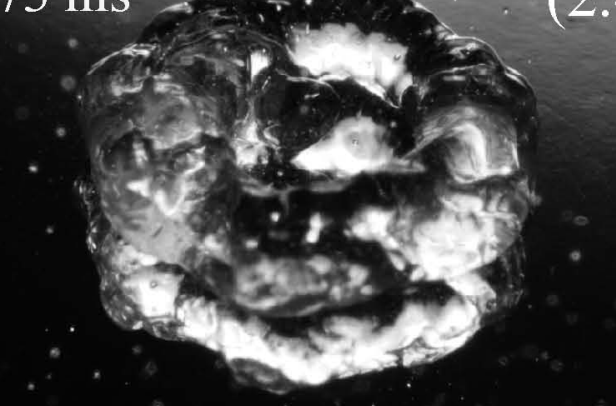

\section{$12.50 \mathrm{~ms}$}

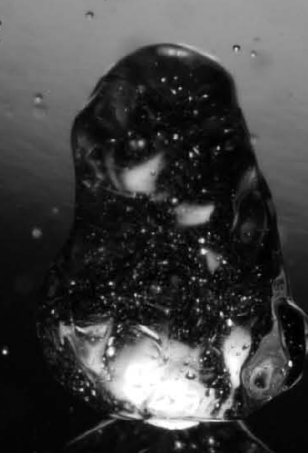

$(4.63)$

$5 \mathrm{~mm}$ 


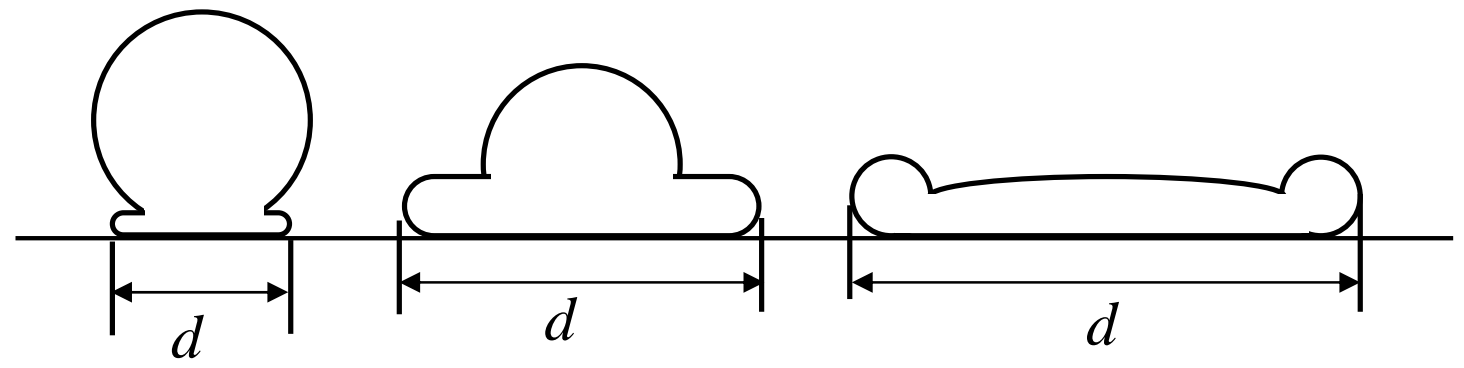

Fig.18(c) 
$0.50 \mathrm{~ms}$

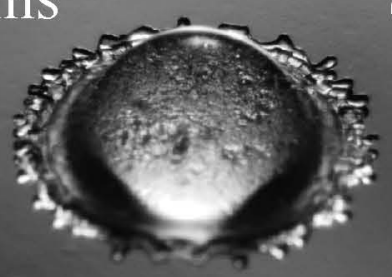

$0.78 \mathrm{~ms}$

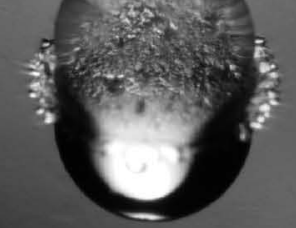

$(0.28)$

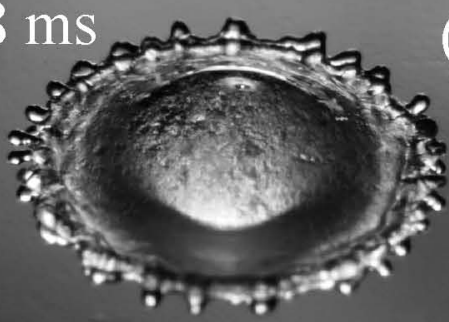

1.

$1.27 \mathrm{msen}_{\mathrm{s}} \mathrm{aras}$

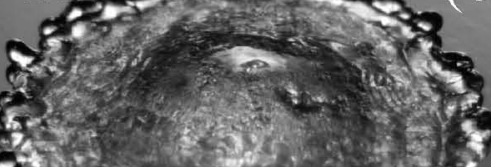

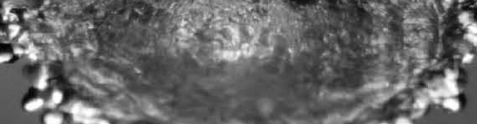
typh

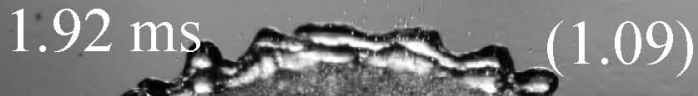 axis?} \&

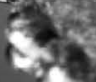

2. 3 $\min 0$

\section{$2.66 \mathrm{~ms}$}

ans

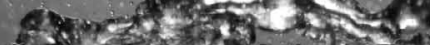

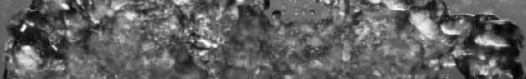
-H. Existing

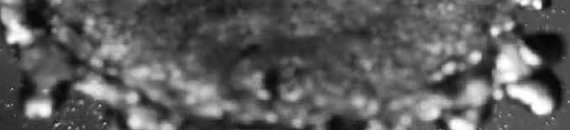
Lo cos of

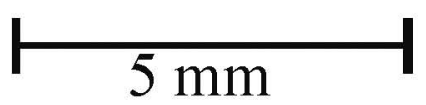

$(0.44)$

$0.72)$ .

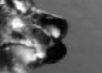

$5.33 \mathrm{~ms} / \mathrm{as}$ (3.02)

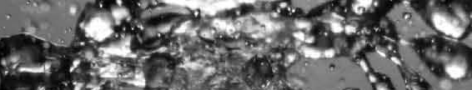
valit?

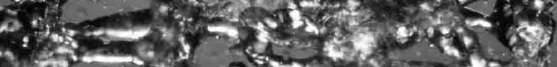

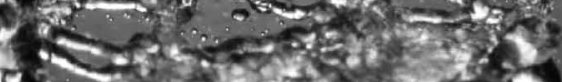

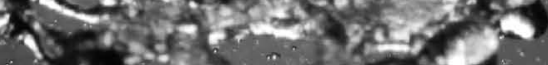

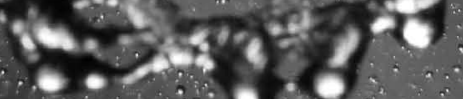
0.0 .0

$4.48 \mathrm{~ms} . \mathrm{s}$ $(2.53)$ $315.03,2$ $3+2=2 x$ 3. $4 \times-202$ $20,1 \times, 0,2$ 3. $\sin ^{2} \sin 9$

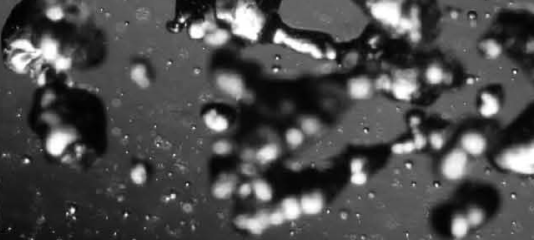
$6.77 \mathrm{~ms}(3.83)$ $-20$.

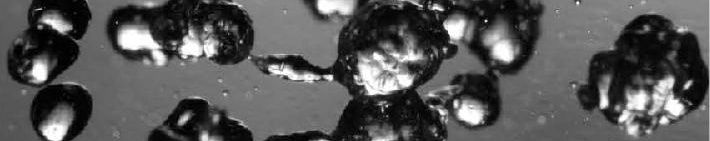
- $81-y^{2} \leq 3$ $\rightarrow i_{-\infty} 8$ $8.98 \mathrm{~ms} 000.08 \%$ as: Fo 80 . 
都大学

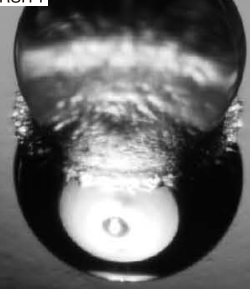

$0.77 \mathrm{~ms}$

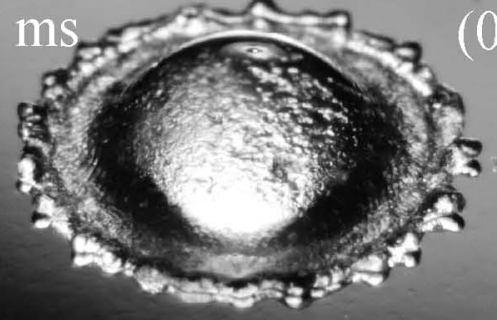

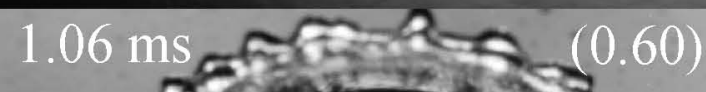

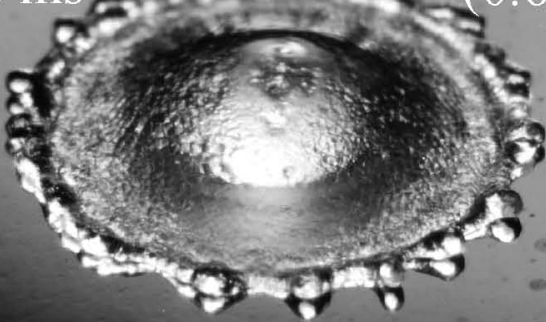

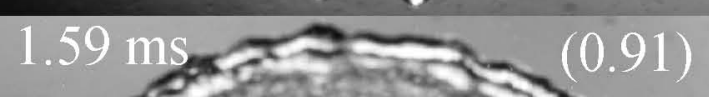

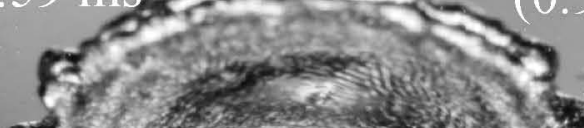

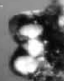

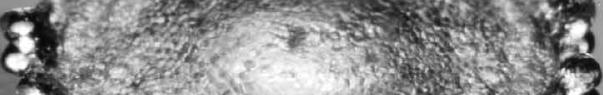

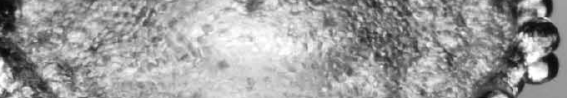

B.

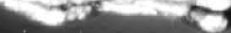

\section{2.}

$8 \mathrm{~ms}$ $60 x+5=05$

a. 350 .

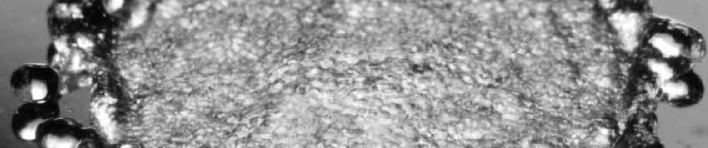

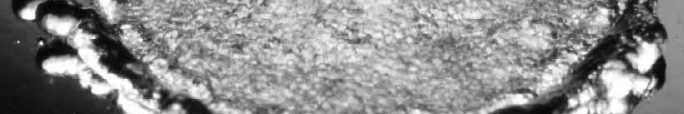

$3=8,2+2 y^{2}$

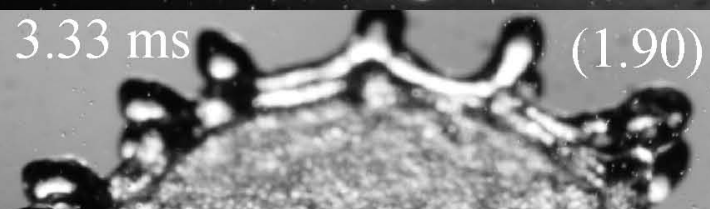

2

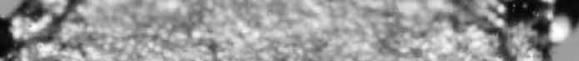

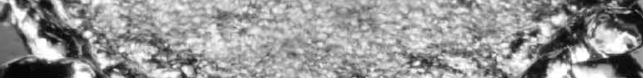

olnis - ins

$\therefore-7 y=120$ 120

0.

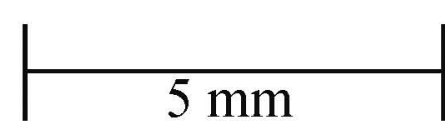

4. 2505

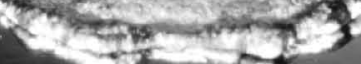

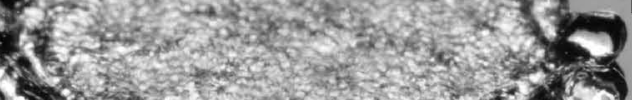

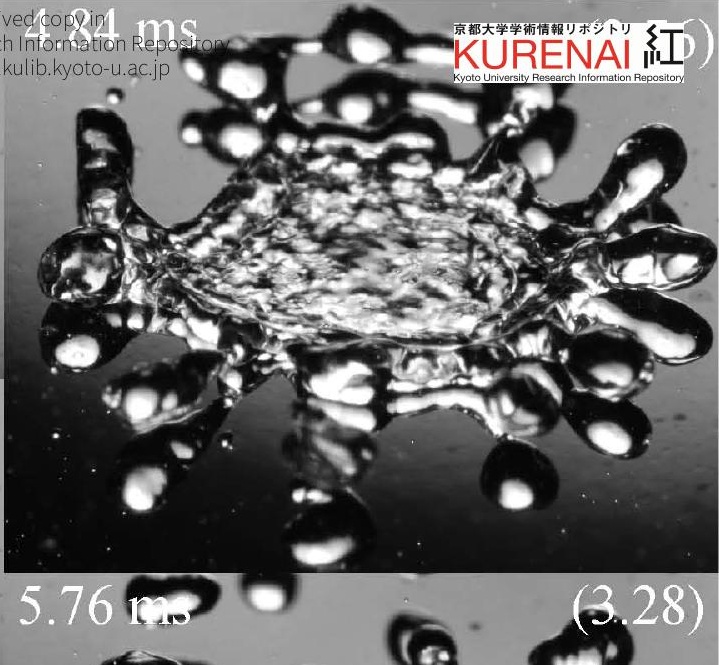

$\Rightarrow=(3.28)$

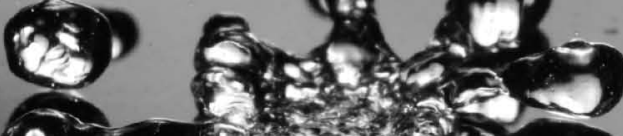

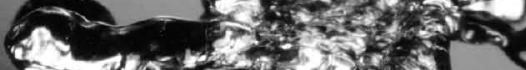

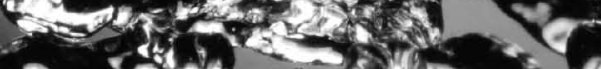

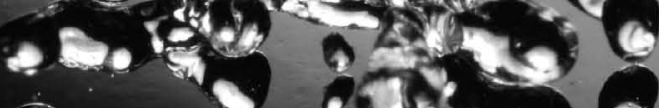

- 0 os on 0

9. $\therefore$ से

$6.45 \mathrm{~ms}(3.68)$

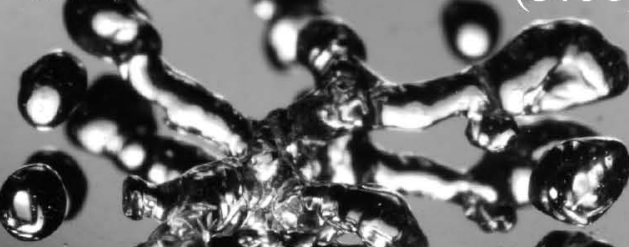

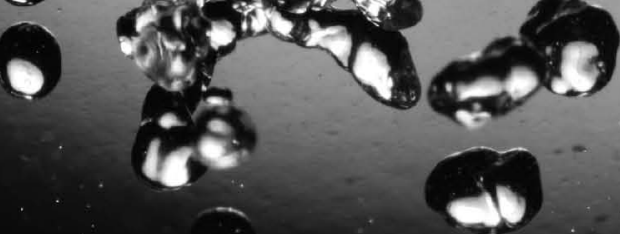

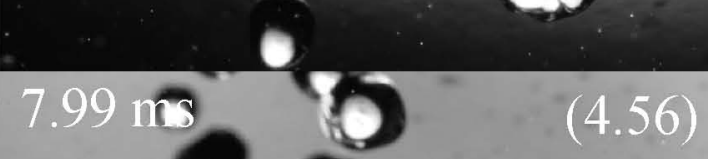

(6) 9 .

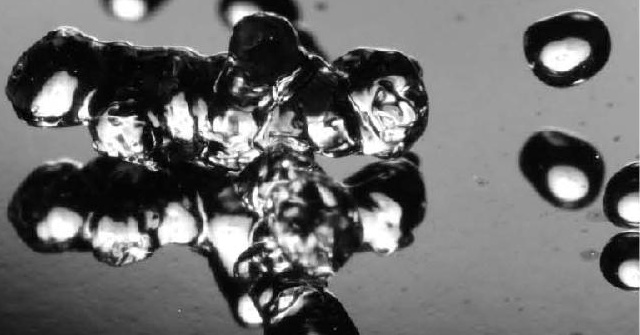

Q

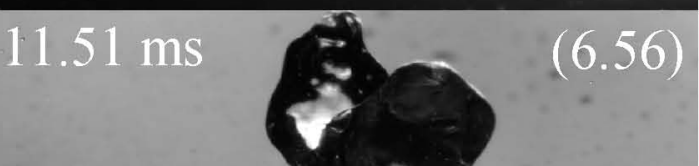

Fig.20 


\section{(2.) 京都大学}

Aselated

$5.13 \mathrm{~m}=0$

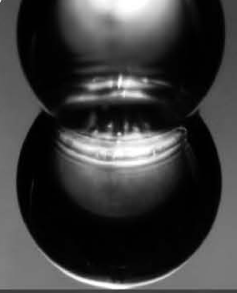

$0.86 \mathrm{~ms}$

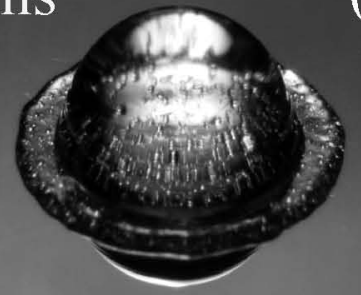

$(0.36)$

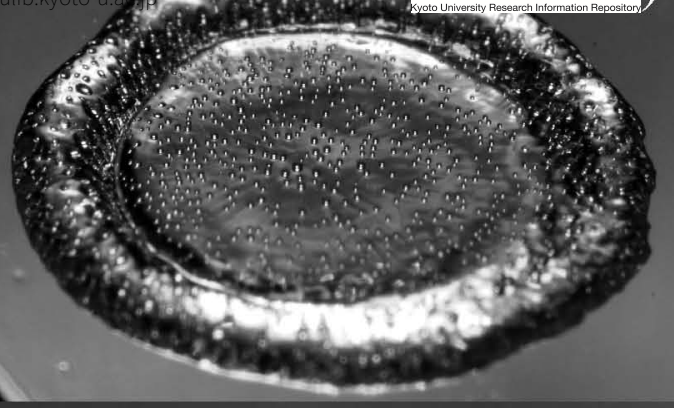

$7.24 \mathrm{~ms}$ (2.99)

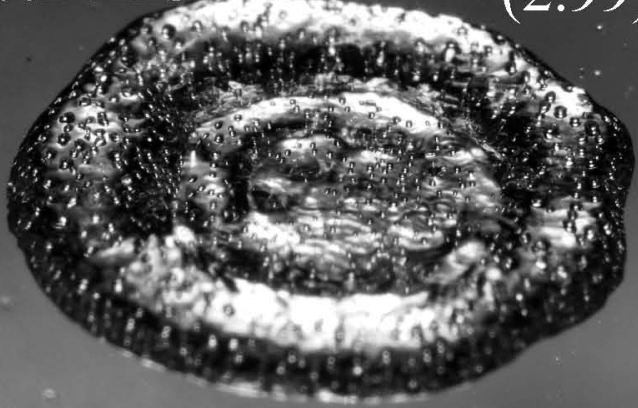

$1.66 \mathrm{~ms}$

$(0.68)$

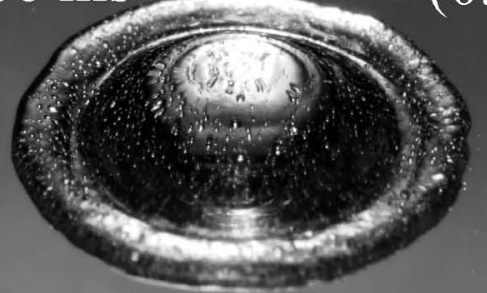

$8.51 \mathrm{~ms}$

1.

$(3.51)$

4000 .

ind

$2.89 \mathrm{~ms}$

(1.19)

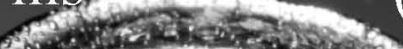

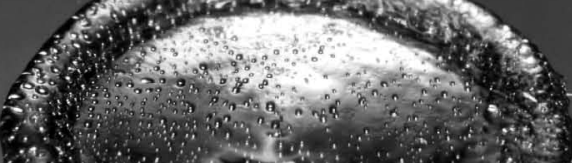
1.

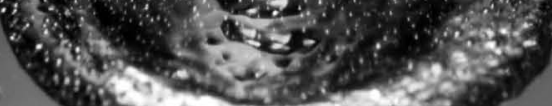

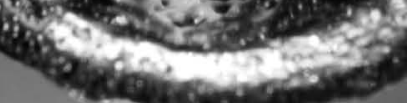

\section{4}

$4.03 \mathrm{~ms}$

(1.66)

$11.74 \mathrm{~ms}$

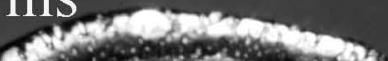

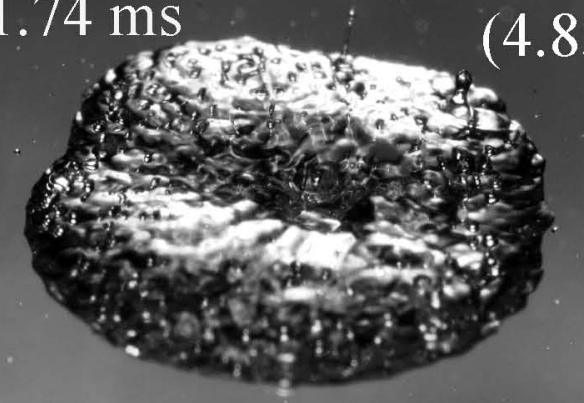

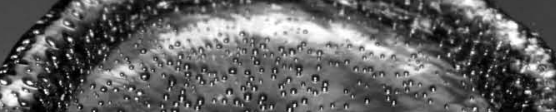

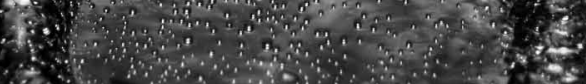

$3+1 \times$ and

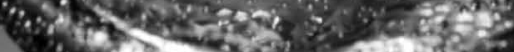

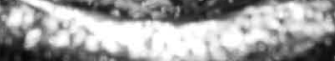

Fig.21

\section{$5 \mathrm{~mm}$}

